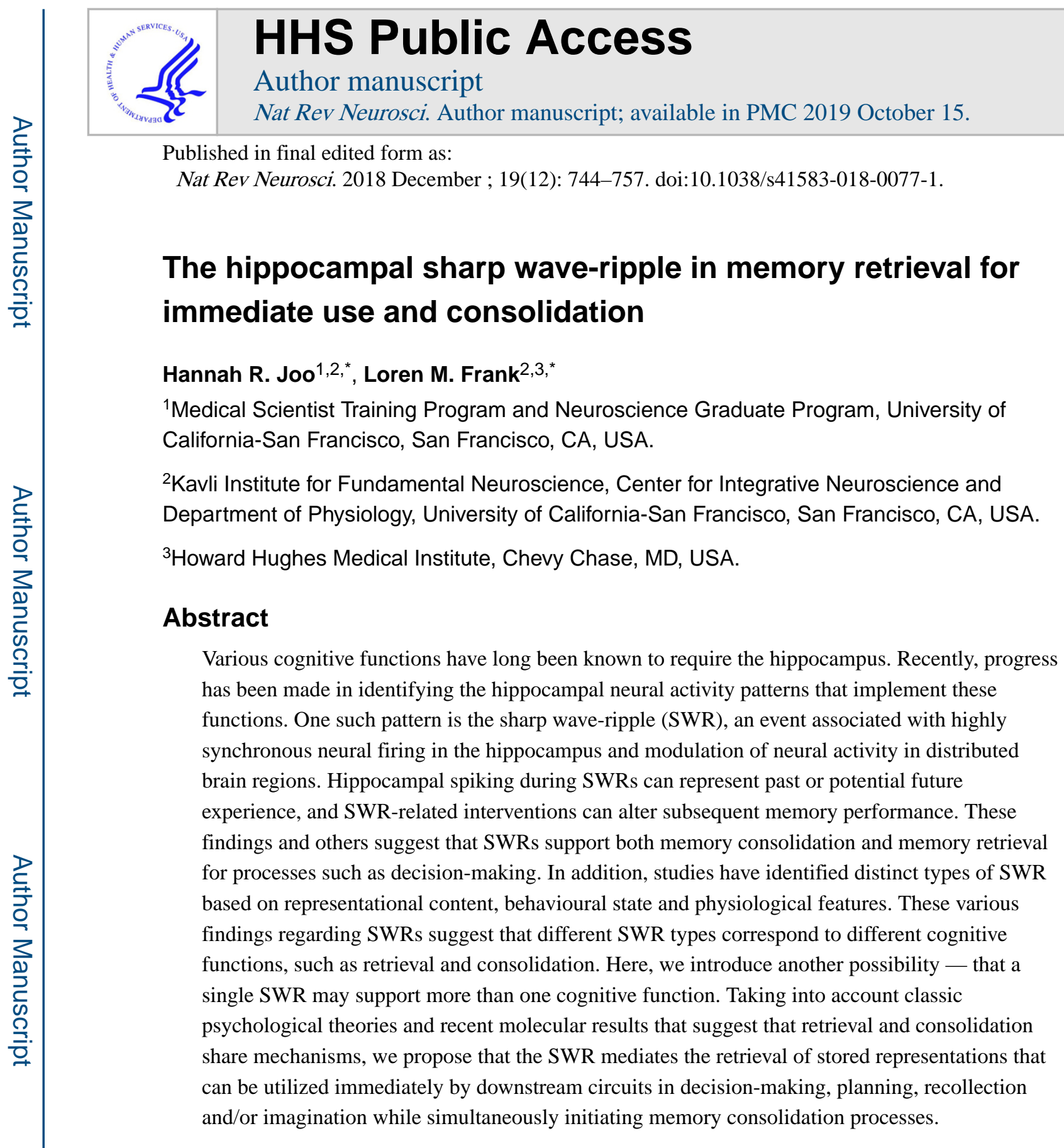

It is not possible for the body to go back or to leap ahead in time, but it is possible for the mind, as it can store and access information about the past to conceive of the future and thus

\footnotetext{
*hannah.joo@ucsf.edu; loren@phy.ucsf.edu.

Author contributions

The authors both researched data for the article, provided substantial contribution to discussion of its content, wrote the article, and reviewed and edited the manuscript before submission.

Competing interests

The authors declare no competing interests.

Publisher's note

Springer Nature remains neutral with regard to jurisdictional claims in published maps and institutional affiliations.

Reviewer information

Nature Reviews Neuroscience thanks L. Colgin, L. Menendez de la Prida and the other anonymous reviewer for their contribution to the peer review of this work.
} 
maintain a sense of self through time. These remarkable abilities depend on memory. The most general organizing framework divides memory into three phases: its initial formation, known as encoding; its ongoing storage; and its retrieval ${ }^{1-4}$. These phases were originally formulated by experimental psychology with reference to animal and human behaviour ${ }^{4}$. Following this tradition, behavioural tests designed to isolate one or more of encoding, storage and retrieval can be used in conjunction with manipulations to identify necessary brain areas or with measurements to identify co-incident neural activity patterns.

A complementary starting point is the observation of neural activity during fairly unconstrained behaviour ${ }^{5-7}$. In contrast to the approach from psychology, this approach does not presuppose cognitive functions, such as consolidation or retrieval. Instead, its focus is neural activity, the features and patterns of which are used to define physiological functions that support memory-associated behaviour. The mapping between the physiological functions and cognitive functions that support memory remains unclear.

The approach from psychology has established that the hippocampus supports certain types of memory-associated behaviour. Complementing these results, the approach from physiology has identified the hippocampal sharp wave-ripple (SWR) as a specific neural activity pattern that supports various memory and cognitive functions, as described in many excellent reviews $^{8-18}$. These previous reviews and the work they summarize have established a link between SWR neural activity and two different phases of memory, consolidation and retrieval, introducing an apparent conflict between knowledge gained from the classic psychological and physiological approaches. Are there functional sub-types of SWR that preferentially subserve retrieval or consolidation? Alternatively, might a single SWR subserve both functions? Here, our aim is to extend the conclusions of earlier work in a new synthesis focused on relating SWRs with particular physiological features, which occur in specific states, to specific memory functions.

We begin with a review of hippocampal function in memory as defined by human lesion studies. Next, we establish working definitions of memory concepts, including encoding, consolidation and retrieval, and we review the dependence of these processes on the hippocampus on the basis of work in rodents and humans. We then introduce the physiological features of the SWR, which have been studied primarily in rodents. In setting out to relate the SWR to specific memory functions, we first define a series of predictions for neural mechanisms that would support consolidation or retrieval. Each of these prediction domains is the focus of a section: behavioural state dependence, necessity in memory-dependent behaviours, representational content and relationship to activity in distributed brain regions. In each section, we summarize what is known about the SWR with respect to the predictions for consolidation and retrieval. On the basis of the results of this exploration, we end with an argument for consideration of an alternative conceptual approach to memory wherein each SWR mediates retrieval in support of both the immediate use of remembered information and the gradual process of memory consolidation. 


\section{The hippocampus and memory}

Damage to the hippocampus, the generative structure of the SWR, has been known for at least 50 years to result in the combination of anterograde and temporally graded retrograde amnesia $^{1,19}$. These findings, primarily based on human lesion studies (for example, of the famous patient $\mathrm{H} . \mathrm{M}^{20}$ ), indicated a specific deficit in what are often characterized as 'relational memories', defined as those memories that store information about complex combinations of stimuli or states ${ }^{21}$. In humans, these include episodic memories, which comprise the subset of declarative memories for specific experiences ${ }^{3,22}$. The findings from the lesion and other studies support three main conclusions. First, the encoding of relational memories requires the hippocampus, accounting for the anterograde amnesia observed in the lesion studies. Second, the hippocampus is also required for the retrieval of these memories for some time after initial storage, accounting for the retrograde amnesia with hippocampal lesions. Third, after the initial formation of memories, during their ongoing storage, memory retrieval gradually shifts from requiring an intact hippocampus to being at least partially independent of it, accounting for the temporally graded nature of retrograde amnesia following such lesions.

During encoding, neural representations of experience must be linked together to capture information about experience as it unfolds in time ${ }^{23}$. Physiologically, encoding is thought to depend on hippocampal mechanisms ${ }^{24-26}$ other than the SWR ${ }^{27-30}$. Encoding is distinct from other memory processes in that it happens first and at most once per event or episode $^{3,31}$, although multiple encoded episodes can contribute to what is thought of as a single memory (for example, each exposure in a fear conditioning task is encoded; the resulting long-term 'fear memory' is probably the result of generalization across these experiences during consolidation ${ }^{32}$ ). By contrast, retrieval and consolidation can occur repeatedly and in alternation throughout the life of a memory ${ }^{33}$.

The adaptive value of memory storage is in its later use, the starting point for which is memory retrieval, specifically defined as the function of accessing information stored in memory. Importantly, retrieval is distinct conceptually ${ }^{34}$ (and probably neurally) from the conscious experience of remembering, or recollection, for which retrieval is necessary but not sufficient. In addition to conscious recollection, retrieval has many other uses. In perhaps its simplest application, retrieval of a single stimulus-response association can drive behaviour directly, as when exposure to a context associated with shock leads to freezing ${ }^{32}$. A more complex computation may be performed when a subject is confronted with multiple options and retrieves specific episodes of past experience for decision-making or planning. Retrieval in some form could also support imagination, which can be understood as the rearrangement or elaboration of stored information in the mental simulation of future possibilities ${ }^{35}$.

Retrieval is typically inferred from behaviour, and behavioural studies indicate that all of the aforementioned retrieval-and-use scenarios require the hippocampus in rodents ${ }^{36}$, monkeys ${ }^{37}$ and humans ${ }^{38-44}$. In some circumstances, the dependence of such memory retrieval-and-use behaviours on the hippocampus is time limited ${ }^{32,45,46}$. The gradual shift in their dependence from the hippocampus to the neocortex, initially inferred from lesion 
studies, is attributed to a hypothetical process known as systems consolidation. The standard model of systems consolidation and its alternatives ${ }^{47}$ describe a process spanning weeks to years that renders memories less liable to disruption (although they remain mutable) $33,48,49$.

Importantly, systems consolidation itself is thought to depend on retrieval ${ }^{4,10,34,50-52}$. Mechanistically, repeatedly retrieving information that is stored in memory is hypothesized to initiate synaptic consolidation processes, including subsequent protein synthesis, that strengthen or weaken specific synapses over minutes to weeks ${ }^{53}$. The standard model proposes that synaptic strengthening, in particular, effects the gradual, but complete, transfer of memories from the hippocampus to the neocortex ${ }^{31,54}$. Alternatives to this model cite findings that some memory-dependent behaviours, particularly those requiring detailed episodic memory, are always compromised following hippocampal lesions and thus may require the hippocampus indefinitely ${ }^{38-55-56}$. Systems consolidation is also associated with the extraction from specific episodes of general features or rules related to stored experiences ${ }^{39,57}$ in more semantic or schema-like representations in the neocortex ${ }^{38}$.

Although this account of memory retrieval and consolidation has its basis in behavioural studies, the extent to which behaviour alone can provide mechanistic insight into memory is limited. A behavioural report of retrieval requires not only retrieval itself but also its successful encoding, likely consolidation, and at least one of its many possible downstream uses. For this reason, behaviour is not a highly sensitive detection method for retrieval; introspection tells us that it is possible to access information from memory without any obvious outward behavioural signs. Neither is behaviour specific to the particular use of retrieval; behavioural expression of simple associations, decision-making, imagination and planning may not be differentiable. Moreover, just as retrieval cannot be reliably inferred from behavioural output, it is not fully predictable from environmental inputs: although memory retrieval can be prompted by experience with contexts or stimuli from the past ${ }^{58,59}$, it does not always occur (often we are distracted; sometimes, we forget). Thus, we can infer from behaviour that consolidation and retrieval occur, but we cannot infer precisely when or how. Here, the behavioural approach is complemented by the study of brain physiology, which has independently identified striking patterns of neural activity that are suggestive of memory function, such as the SWR.

\section{Sharp wave-ripples}

\section{Physiology of the SWR.}

For at least 50 years, the extra-cellular local field potential (LFP) has been used to relate neural and behavioural phenomena ${ }^{6,7}$. In early work, large, brief deflections in the hippocampal LFP were observed during periods of rest ${ }^{5,6}$; this striking LFP pattern was termed large-irregular activity (LIA). The defining activity during LIA in the hippocampus is a more specific pattern known as the $\mathrm{SWR}^{60}$, the properties of which have been studied primarily in the rodent (but see Box 1).

The sharp wave component of the SWR is an extracellularly recorded event that corresponds to the summed, synchronous depolarization of a large fraction of the neurons in the CA1 subregion of the hippocampus ${ }^{6,60-63}$. In permissive network states ${ }^{8}$, CA1 activity can be 
driven by activity in upstream CA3 that is independent of external inputs ${ }^{60,64}$. Such activity can be modulated by activity in CA2 $\left(\mathrm{REP}^{65}\right)$ and the den-tate gyrus ${ }^{66}$. The strong recurrent connectivity in CA3 (REFS ${ }^{67,68}$ ) is thought to allow the increased activity of fairly few pyramidal cells to spread rapidly through the region. The same activity from CA3 that excites a large subset of CA1 pyramidal cells ${ }^{69}$ also excites interneurons, resulting in the oscillatory excitation and inhibition of interneuron-coordinated pyramidal cell ensembles that manifest as the co-incident ripple, a high-amplitude $150-250 \mathrm{~Hz}$ oscillation ${ }^{6,63,70-74}$.

The presence of high power in the ripple band is itself often used as a marker for SWRs (usually using a threshold between 3 and 9 s.d. above the mean) ${ }^{75,76}$. The distribution of ripple band power is not, however, bimodal. Rather, it is approximately log-normal with a long tail towards high values ${ }^{76}$. The application of a threshold to ripple power, therefore, should not be understood as discriminating SWR and non-SWR events with perfect accuracy. Nonetheless, the properties of spiking and LFP activity observed during SWRs are consistent across a variety of studies that use different thresholds ${ }^{8}$.

On the basis of features that we review below, SWR-associated neural activity has been proposed to support memory consolidation, retrieval, planning and imagination $8,9,15-17,77$. In parallel, different types of SWR have been identified on the basis of representational and physiological characteristics. However, whether there is a simple mapping from memory function to SWR type remains unclear. This question is particularly important because of its implications for our understanding of the relationship between retrieval and consolidation. Consolidation requires retrieval. Does retrieval necessarily lead to consolidation? An absence of SWR functional types would suggest that, for this particular candidate memory mechanism, retrieval and consolidation are effected together.

\section{SWR occurrence depends on experience and behavioural state.}

The SWR is a physiological event of subsecond duration. To the extent that an SWR supports systems consolidation, it would likely be by initiation of slower synaptic consolidation processes ${ }^{78}$. In this Review, we differentiate these hypothetical consolidationpromoting events (consolidation events) from consolidation itself, the process of strengthening a memory that is thought to correspond to synaptic changes. We expect consolidation events to occur with greater strength or frequency following any experience that would be adaptive to remember, such as a novel, rewarding, punishing or otherwise instructive experience ${ }^{79}$. Because sleep has been shown to have a memory-strengthening effect ${ }^{57}$, we expect consolidation events to occur during sleep. However, it is possible that they also occur during wake.

Because consolidation is thought to require retrieval, any period when consolidation events are expected on the basis of state or behaviour is also expected to contain retrieval events; similar to consolidation events, retrieval events are expected to occur following novelty, reward and punishment as well as in sleep and probably also in wake. Therefore, these timing-based predictions cannot discriminate SWR function in consolidation from function in the retrieval that supports it. 
For retrieval in uses other than consolidation, similar dependencies on behavioural state are expected. Because retrieval is necessary for processes that occur in the awake state, such as decision-making, retrieval events are expected to occur then. Retrieval events for decisionmaking might also be expected to decline with novelty, occurring more often in situations early in learning before general rules have been learned ${ }^{80,81}$, as this is when specific memories may be used to guide decisions. Likewise, the use of retrieval in recollection may be more frequent following reward, as these events may be preferentially recollected ${ }^{82}$. Retrieval events may also occur during sleep, as when elements of waking experiences recur in dreams, and thus could support the previously reported phenomenon of sleep insight ${ }^{83}$. These possibilities demonstrate that predictions based on behavioural state or experience alone cannot definitively differentiate a mechanism that supports retrieval for consolidation from retrieval for other uses - just as such predictions cannot distinguish retrieval events in consolidation from consolidation events themselves. Furthermore, because consolidation and retrieval events are expected to occur in the same behavioural states, a single mechanism could exist to support both simultaneously.

Work in rodents has demonstrated that SWRs occur most frequently during slow-wave sleep, least frequently during running, and at an intermediate rate, occurring once every few seconds, during periods of quiet rest ${ }^{76,84}$. This pattern of occurrence is regulated by modulatory factors ${ }^{85}$ including cholinergic tone ${ }^{10,86}$, which tends to be higher during movement ${ }^{87}$. Cholinergic modulation has also been speculated to explain a recent report that SWR occurrence is entrained by breathing ${ }^{88}$. SWRs typically occur more frequently during and after novel experiences ${ }^{76,89-91}$, although the SWR rate has been reported in some tasks to increase over the course of multiple traversals of a familiar path ${ }^{92}$. An increase in SWR rate is also seen immediately after receipt of a reward, particularly if it occurs in an unfamiliar location ${ }^{93}$ (Fig. 1).

Together, these findings indicate that the SWR rate is at its highest in the contexts of novelty and reward, consistent with functions in both consolidation and retrieval. The increase in SWR rate immediately following reward is consistent with theoretical predictions for a consolidation mechanism that would be particularly effective in linking extended actions to their outcomes, a specialized information storage problem known as credit assignment ${ }^{93,94}$. However, a higher SWR rate after reward could also correspond to retrieval for recollection, and a higher SWR rate during novel experience could also correspond to retrieval for decision-making.

\section{SWRs are necessary for memory performance and stable representations.}

If the SWR supports consolidation, either as a retrieval mechanism or in some other capacity, it is expected to be necessary for memory-dependent behaviours and changes in synaptic strength, the established molecular correlates of learning. Under the standard model, a mechanism for systems consolidation is also expected to be necessary for the renormalization of synapses in the hippocampus and, in parallel, the alteration and stabilization of synapses in extrahippocampal structures, particularly the neocortex ${ }^{78,95,96}$. Alternatively, if the SWR is a mechanism for memory retrieval for use in functions other 
than consolidation, it is likewise expected to be necessary for memory-dependent behaviours but not for plasticity.

Studies that have interrupted or disrupted the structure of SWRs during sleep have demonstrated their necessity for memory-dependent behaviours and have been interpreted as evidence of a consolidation function. The first of these studies truncated SWRs by electrical stimulation of CA3-CA3 connections in the ventral hippocampal commissure. Across many days of learning, SWRs were truncated during hour-long sleep or rest periods following experience. This truncation of SWRs resulted in slower learning in hippocampus-dependent spatial memory tasks ${ }^{97.98}$. SWR disruption by other methods, including suppression of CA3 output to CA1 $\left(\mathrm{REF}^{99}\right)$. and optogenetic activation of the locus coeruleus ${ }^{100}$ or median raphe ${ }^{85}$ during post-behaviour sleep, has a similar effect. Interestingly, when SWRs are disrupted in sleep after learning, but not after a random foraging task, there is a subsequent increase in their rate, suggesting the existence of homeostatic-like control of SWRs that is set on the basis of learning ${ }^{101}$. A recent gain-of-function study also demonstrated that electrical stimulation of the medial prefrontal cortex (mPFC) immediately after each SWR during sleep led to an increase in coordinated activity between the mPFC and hippocampus as well as an improvement in memory for a briefly experienced set of objects in a context ${ }^{102}$.

Disruption of SWRs during awake behaviour also impairs learning and performance in spatial memory tasks ${ }^{103,104}$. SWRs were demonstrated to be necessary for a normal rate of initial learning of a spatial alternation and, in a separate group of animals already trained in the task, for continued performance ${ }^{103,105}$. Similarly, delivery of a strong light stimulus after SWRs disrupted learning in a trace eyeblink conditioning task, suggesting that the period extending hundreds of milliseconds following an SWR is important for memory processes ${ }^{104}$. In further support of this hypothesis, gain-of-function experiments showed that presentation of conditioned stimulus-unconditioned stimulus pairings specifically following SWR events led to an acceleration in learning (but also slowed extinction) ${ }^{106}$. The disruption of SWRs that is observed in both sleep and wake in models of diseases with memory symptoms also suggests that SWRs contribute to memory (Box 2).

There is complementary evidence that SWRs contribute to stabilization of representations that are formed during experience. In awake behaving rodents, SWRs can contribute to stabilization of place fields, the spatial representations typical of principal cells in the hippocampus ('place cells') 107,108. During awake behaviour for mice performing a spatial memory task, optogenetic silencing of principal neurons in CA1 during SWRs reduced the stability of their place representations ${ }^{109}$, and following this period of silencing, active hippocampal neurons were more likely to have altered place fields ${ }^{107}$ when the mice were re-exposed to the environment. Similar manipulations during sleep have suggested that the subset of place cell ensembles that are not yet fully stable at the end of an initial novel experience can be destabilized by optogenetic suppression of neural activity during SWRs ${ }^{110}$. By contrast, ensembles that were stable by the end of a novel experience were not affected, perhaps explaining why another group found that optogenetic suppression of CA1 principal neurons during sleep SWRs had no effect on spatial representations ${ }^{111}$. 
The stabilization of these representations probably results from changes in synaptic strength, but studies have differed in their reported effects of SWRs on synaptic plasticity in the hippocampus. SWR-like activity in vitro can promote intrahippocampal synaptic potentiation ${ }^{112,113}$, but recent findings have indicated that sleep SWRs can also contribute to the widespread downscaling of hippocampal synapses ${ }^{114}$, which substantiates a previously developed model ${ }^{115}$ predicting that SWRs induce downscaling of intrahippocampal synapses and potentiation of extrahippocampal synapses. The possibility that SWRs could drive local synaptic renormalization (perhaps to reset hippocampal synapses so that new learning can occur ${ }^{114-116}$ ) is also consistent with the clearance of a hippocampal memory trace and simultaneous consolidation in neocortex predicted by the standard model of systems consolidation. Whether awake SWRs can have the same effect is unknown, as wake and sleep are different neuromodulatory states and SWRs probably differ, and/or have different effects, in each of these states ${ }^{10,18}$. For both sleep and wake, it is unknown whether some synapses might be maintained or strengthened while others are weakened.

The effects of SWR disruption on behaviour and hippocampal place representation constitute strong support for a memory function of SWRs in both wake and sleep. SWR disruption and augmentation effects on learning and synaptic plasticity indicate a consolidation function in particular for at least a subset of SWRs. However, it is possible that these or a different subpopulation of SWRs have an additional function in retrieval for other uses. For example, to date, published awake SWR disruption experiments have interrupted all SWRs. The detriment in performance resulting from this disruption could therefore be explained instead by an effect on retrieval in support of decision-making, particularly for those studies in which SWR disruption occurred after rule learning was complete and resulted in a decline in otherwise stable performance ${ }^{103}$. Thus, although SWR disruption studies indicate that SWRs support memory in both sleep and wake, these studies do not specifically indicate retrieval for consolidation versus other use or a function other than retrieval in support of consolidation.

\section{Hippocampal spiking during an SWR can represent previous experience.}

Mechanistically, the most readily recognizable form that retrieval could take is the precise repetition of the activity pattern that was observed during the experience itself ${ }^{52}$. Indeed, retrieval is thought to occur by reactivation of neural activity patterns in the hippocampus that correspond to those that occurred during a previous experience, a possibility foundational to modern engram theory ${ }^{58,117}$. This activity, in turn, is thought to reactivate hippocampal-cortical and sub-cortical activity patterns to represent the multisensory features of a memory. In synaptic and systems consolidation, it is likewise the repeated reactivation of the hippocampal-cortical patterns stored during an experience ${ }^{31,78}$ that is hypothesized to create and strengthen the intrahippocampal and hippocampal-cortical synapses that constitute the memory trace. This correspondence further highlights that the hypothetical consolidation event and the retrieval event are effectively identical and that the requirement for retrieval in consolidation is satisfied by the repetition of such events. We next review the evidence that SWR activity may constitute such an event. 
During SWRs, more than during any other period of activity, sequences of neural spiking activity recapitulate those seen during prior experience. These striking reactivations were originally observed at the level of single cells ${ }^{118}$ and cell pairs ${ }^{119}$ but also occur at the level of ensembles ${ }^{120,121}$. Individual reactivation events can represent either specific locations in space $^{121,122}$ or can 'replay' long sequences of place cell activity that recapitulate entire spatial trajectories ${ }^{77,94,123-127}$. Replay events can also represent long, extended experiences, with events spanning multiple SWRs ${ }^{127,128}$. Such replay of past experience is seen in a subset of SWRs in both waking and sleep, although replay in sleep is a less accurate recapitulation of awake activity patterns ${ }^{125,129}$. The representation of past experience by replay activity suggests that it is a critical component of the SWR contribution to memory and that replay variants may correspond to different SWR memory functions.

Replay events can reactivate representations corresponding to either local trajectories beginning at the animal's current location or remote trajectories, defined as those that begin far from the animal's location ${ }^{125,126}$ or in an entirely different environment ${ }^{123,125,130,131}$. When spatial sequences correspond to the current environment, $80 \%$ of identified replay events begin with representations of the animal's current position ${ }^{94,124,125,127}$. These events then extend towards locations farther from the animal, with a bias for representation of future goal locations ${ }^{77}$. Remote replay occurs in both wake and sleep ${ }^{125,129}$. Behavioural state influences replay content, in that events that occur in close temporal proximity to movement more often originate at the animal's current location (that is, they are more often local) ${ }^{125,132}$.

Replay events also vary in the represented direction of movement (FIG. 2). In linear environments, hippocampal place cells gradually develop directionally biased firing patterns, with a higher firing rate when the animal traverses the place field in one direction of motion than in the reverse ${ }^{133,134}$. These biases in firing make it possible to use ensemble spiking during replay events to infer not only the represented location of the animal but also the direction of movement. These analyses have revealed that awake replay can occur in both the same direction as the original traversal (forward replay) and the opposite direction, which may never have occurred during behaviour (reverse replay) ${ }^{94,124,127}$.

A functional difference for forward and reverse replay in wake is suggested by their independent modulation: increases in reward magnitude increase the rate of local, reverse replay events and decreases in reward magnitude reduce it, with no effect on forward replay events ${ }^{135}$. This result is consistent with the hypothesis that local, reverse replay following an outcome can function as a consolidation mechanism that is specialized to the problem of credit assignment, wherein outcomes must be linked to the actions that led to them. During replay, earlier reactivation of cells with place representations that are physically closer to the outcome location is hypothesized to facilitate the strengthening of synapses with co-active cells representing reward or punishment, while the specificity for movement towards the outcome location preserves directionality ${ }^{94}$. Consistent with credit assignment or consolidation in general, the intensity of reactivation during SWRs can be related to the reorganization of spatial representations and to memory for previously rewarded locations ${ }^{121}$. 
In contrast to reverse replay, local replay events in the forward direction during wake have been correlated with subsequent behaviour, suggesting that they function in retrieval of previous experiences that occurred in the same context for immediate decision-making or planning ${ }^{77}$. These events could also function in retrieval for conscious recollection, or 'mental time travel' (that is, the ability to be in one location and simultaneously remember a past experience that may have occurred in another) ${ }^{22,77,136,137}$ (but see REF. ${ }^{8}$ ). Consistent with this possibility, replays are enriched for representation of immediate future choices ${ }^{77}$, and more intense activity during these events can be predictive of a subsequent correct choice $^{138}$. Further, the awake replay of an upcoming location associated with shock is predictive of a subsequent change in movement direction ${ }^{139}$.

Although reverse and forward replay events are both common during wake, reverse events are seen only infrequently during sleep ${ }^{123,140}$. The consolidation function of sleep is therefore expected to be carried out by forward replay events. However, the specific nature of this hypothesized consolidation remains unclear. Consistent with expectations for consolidation, the intensity of reactivation during sleep SWRs is related to the reorganization of spatial representations and to memory for previously rewarded locations ${ }^{121}$. However, the fidelity of replay events during sleep is, on average, much lower than of those in wake ${ }^{125}$, prompting speculation that sleep events represent sequences including elements of multiple experiences to support consolidation in the form of generalization across them ${ }^{18,125}$.

\section{Spiking during SWRs can represent actual or alternative future actions.}

Mechanistically, the imagination function thought to be supported by the hippocampus ${ }^{141}$ could begin with a retrieval process wherein stored information is accessed and proceeds with the rearrangement of that information in novel combinations. These imagined scenarios might correspond to potential future choices, such as when planning new routes to a goal location. As in veridical retrieval, this neural activity would likewise be expected to reactivate patterns of activity throughout the brain.

Consistent with these predictions for an imagination mechanism, SWRs can contain sequences corresponding to trajectory events that represent novel paths that have not been previously traversed by the animal ${ }^{77,126}$. Such prospective trajectory events suggest a function beyond veridical retrieval for decision-making or consolidation, wherein retrieval and rearrangement of previously stored representations support a process such as imagination. In addition to novel sequences pertaining to the local environment, there have been reports of what can be understood as remote prospective events, or 'preplay', in which activity sequences that will occur in a subsequent novel experience are seen during sleep before the experience ${ }^{142-144}$, although this remains a topic of debate in the field ${ }^{145}$. We return to the issue of imagination in the final section.

\section{SWR activity engages extrahippocampal areas.}

A key prediction shared by mechanisms for consolidation and for retrieval in other uses is the modulation of neural activity in distributed brain regions. In systems consolidation, the reactivation of hippocampal-cortical patterns for synaptic stabilization necessarily requires correlated activity. Retrieval is likewise thought to depend on hippocampal coordination of 
cortical (and likely subcortical) networks to represent the various aspects of experience, including different sensory modalities and extracted features ${ }^{146}$, a possibility consistent with functional MRI (fMRI) studies of human retrieval ${ }^{147}$. Both retrieval and consolidation can be influenced by external stimuli, including during sleep ${ }^{57}$. Mechanistically, this is thought to depend on inputs to the hippocampus, such as those from the entorhinal cortex (EC), that can bias the local network to reactivate specific representations (potentially by a patterncompletion process $)^{95,148}$. Distributed activity in consolidation is expected to result in strengthened synapses, whereas such activity in retrieval for other uses is not expected to have such an effect. Note also that for an SWR typology based on replay content to be meaningful, different subsets of SWRs should be associated with different downstream effects, with only one subset of SWRs (for example, those with reverse replays in wake) associated with synaptic consolidation.

Consistent with these predictions, changes in neural activity throughout the brain have been observed during SWRs. Electrophysiological studies have identified coordination between hippocampal SWRs and neocortical sleep spindle events ${ }^{149,150}$ as well as coordinated hippocampal and extrahippocampal modulation of spiking activity at the time of SWRs in the dentate gyrus ${ }^{66,151,152}$, deep (but not superficial ${ }^{153,154}$ ) $\mathrm{EC}^{155,156}$, orbitofrontal cortex $^{157}$, mPFC $^{129,149,158,159}$, anterior cingulate cortex (ACC) ${ }^{122,160,161}$, auditory cortex $^{162}$, parietal cortex ${ }^{163}$, ventral striatum ${ }^{164,165}$ and the ventral tegmental area (VTA) ${ }^{166}$.

In some extrahippocampal structures, stronger co-activity with hippocampal cells has been reported in wake than in sleep despite the association of SWRs with sleep spindles ${ }^{129}$.

Patterns of hippocampalprefrontal cortex (PFC) co-activity seen during behaviour were more strongly re-expressed during awake than sleep SWRs ${ }^{129}$, mirroring the finding of more veridical hippocampal replay in awake SWRs ${ }^{125}$. Similarly, SWR-associated reactivation of VTA neurons was present during both wake and sleep ${ }^{167}$, although it was more prevalent during wake ${ }^{166}$.

A recent study also found learning-related coordination of SWRs and high-frequency activity specifically in association cortices during sleep ${ }^{168}$. Additional studies have identified patterns of coordinated hippocampal-cortical activity that are consistent with SWR activity, but these studies did not detect SWR events ${ }^{130,169}$. All of these studies report that hippocampal and cortical or subcortical neurons that fired together during waking experience also fired together during subsequent SWRs or reactivation events, as expected in retrieval for consolidation (or for any other use). Complementing this result, combined hippocampal electrophysiological recordings and fMRI in primates revealed changes in blood-oxygen-level-dependent (BOLD) activity around the time of SWRs across virtually all cortical areas and many subcortical areas ${ }^{170}$.

The specific subset of cells engaged in SWR-coordinated activity also changes with learning. Early in learning, hippocampal-PFC co-activity patterns during SWRs are correlated with co-activity during behaviour, suggesting a simple Hebbian association mechanism ${ }^{159}$. Later, once the environment and task are familiar, this relationship becomes much weaker ${ }^{129}$, with a subset of PFC neurons that encode general features of the environment and task showing more specific engagement during SWRs ${ }^{171}$. The resulting 
hippocampal-PFC co-activity preferentially links hippocampal activity patterns representing specific locations with cortical activity patterns that generalize across a set of locations.

Studies of the precise timing of cortical activity relative to hippocampal activity during an SWR have suggested that cortical activity influences subsequent hippocampal SWR activity. During sleep, hippocampal SWRs often occur immediately after transitions from cortical down states to cortical up states ${ }^{172}$, and increases in hippocampal spiking can occur as much as 200 milliseconds after increases in spiking in sensory cortical areas ${ }^{130,162,173,174}$. By contrast, although some PFC and ACC neurons appear to increase in activity before SWRs in both wake ${ }^{122}$ and sleep ${ }^{129,161}$, SWR-related PFC activity has most often been reported to follow, rather than precede, SWR-related hippocampal activity during both wake ${ }^{159}$ and sleep ${ }^{158,170,175}$. However, the overall temporal offsets for the PFC are small $(\sim 15$ milliseconds) compared with those for the sensory cortex ( 200 milliseconds).

One possible explanation for these inconsistent reports arises from the recent discovery of a cortical-hippocampal-cortical loop of information transmission. It was previously known that hippocampal activity could be biased by sound presentations during sleep ${ }^{176}$, but the mechanism was unknown. Recently, it was discovered that in the auditory cortex, patterns of activity before SWRs can be used to predict subsequent hippocampal SWR activity and that hippocampal SWR activity in turn predicts post-SWR cortical activity ${ }^{162}$. These findings suggest a cortical-hippocampal-cortical loop of information transmission around the time of sleep SWRs, in which cortical activity can cue hippocampal SWR activity, which in turn drives broad activation of cortical areas. This loop has been proposed to support cortical consolidation ${ }^{14}$. It is also possible that such a loop could explain differences in neocortical activity relative to SWRs if reactivation of cortex by the hippocampus recruits association areas that were not initially active (a possibility reminiscent of one element of hippocampal indexing theory ${ }^{177}$ ).

In the same regions where spiking rates increase in coordination with SWRs, separate populations of cells simultaneously decrease firing rate ${ }^{129,159,172,178}$. These decreases occur specifically for cells that are most active immediately before SWRs, and in both the hippocampus and the PFC these neurons encode information related to the animal's current location. This observation is consistent with the expectation that, during retrieval, processing of current sensory information might be suppressed.

\section{Outstanding issues}

Evidence supports the current view that the SWR is a principal network-level mechanism for reinstatement of stored representations to support both awake and sleep memory processes ${ }^{7,51,179}$. However, in the context of awake retrieval, issues related to its timing indicate that it is not the sole mechanism. SWRs take up only a relatively small fraction of the total time of awake experience (at most a few percent) ${ }^{76}$ and occur very infrequently during movement. There is no evidence that memory and cognition are limited to periods of stillness; thus, awake retrieval probably engages additional mechanisms ${ }^{7}$. The ordered activations of place cells also observed during theta ('theta sequences' ${ }^{180}$ ) are an attractive candidate activity pattern that could support awake retrieval-and-use processes; indeed, the 
content of these sequences can predict subsequent choice ${ }^{181,182}$. This finding is also consistent with observations of intact SWR sequences following manipulations that impair theta sequences and performance in a memory task ${ }^{183}$.

Even during immobility, the SWR may not be strictly necessary for learning and memory. Animals can still learn a spatial task when awake SWRs are disrupted, albeit at a slower pace $^{103}$ (but see REF. ${ }^{104}$ ). Similarly, the observation of correct trials during which no SWRs occur suggests that the SWR is not required for trial-by-trial decision-making ${ }^{184}$. These results could be explained by incomplete SWR interruption or detection ${ }^{185}$, however, or by compensation for an absence of SWRs by other mechanisms ${ }^{80,81}$.

The evocative pairing of replay activity with the plasticity potential of the SWR also makes it tempting to leap to the conclusion that the SWR is a privileged period for replay and that every SWR contains a single replay event that is retrieved for decision-making and/or systems consolidation. Although many SWRs are associated with reactivation of activity patterns representing past experience, studies typically report that only 10-40\% meet statistical criteria for replay ${ }^{77,94,123-127}$ and that reactivation events can occur outside of identified SWRs ${ }^{77}$. It is also possible that some events cannot be decoded spatially because they correspond to trajectories that were not measured by the experimenter or are not spatial in nature ${ }^{186,187}$. Regardless, it seems likely that many SWRs do not contain spiking sequences consistent with a single, discrete past or potential future experience.

Another possibility is that SWRs without detectable replay content correspond to retrieval events for content with representations that have mutated over time to the point they no longer match the activity that was recorded during the original experience. Indeed, place representations can change over days ${ }^{188}$. Such replays would be undetectable, but still functional, and could explain how replay, which has been observed to decline significantly in rate during the 18 hours following experience ${ }^{125}$, could still contribute to a systems consolidation process extending weeks to years after an experience.

Finally, although there is evidence of the brain-wide coordination of activity expected during retrieval and consolidation at the time of the SWR, there is no evidence to suggest that different replay types correspond to different patterns of neural activity in areas downstream of the hippocampus. Recently, work in non-human primates has identified four SWR event subtypes, defined by the timing of the ripple relative to the sharp wave, that are associated with different patterns of cortical and subcortical activity ${ }^{189}$. A rodent study has identified subsets of SWR in which hippocampal-cortical patterns corresponding to movement versus immobility are reactivated separately ${ }^{122}$. Regarding the question of consolidation versus retrieval, however, we are aware of no strong evidence to suggest that any specific sub-type of SWR is exclusively associated with the plasticity expected in consolidation or with behaviour indicating the planning and decision-making associated with awake use of retrieved memories. 


\section{SWRs, retrieval and consolidation}

In modern work, memory retrieval and consolidation are often conceptualized as distinct processes that occur on different timescales - a retrieval event is understood to take place in milliseconds ${ }^{52,190,191}$, whereas consolidation may take hours to years (but see REF. ${ }^{192}$ ). Furthermore, the effect of retrieval is thought to be a transient change in activity for immediate use, whereas consolidation is thought to effect lasting change. However, the two processes share a fundamental similarity that has long been hypothesized in experimental psychology $4,34,193$ : the neural activity representing a previous experience that is reinstated in retrieval is thought to be reinstated repeatedly in consolidation to strengthen associations and synapses (for more on the essential function of repetition in biological and artificial learning systems, see BOX 3).

SWR-associated replay is a prime candidate for that reinstatement ${ }^{10,50,51}$; the basic function of the SWR seems to be retrieval. Behavioural results establish that such retrieval can be used to support consolidation in sleep ${ }^{97,98,121}$ and in wake ${ }^{15,103,109,110,126}$ and to support other uses including decision-making in wake ${ }^{77,103,139}$. Replay during sleep could support a more creative variant of planning, such as imagination, that might activate elements of multiple experiences in novel conjunctions. Previous work has not clearly addressed whether these varied retrieval-based functions are achieved by distinct functional types of SWR that would, for example, subserve exclusively retrieval for consolidation versus retrieval for decision-making $15,16,18,194$. Although such type splitting is possible given the diversity in representational content and physiological properties of the SWR, as well as the behavioural states in which they occur $8,65,122,127,189,195-197$, we conclude that there is not yet evidence to suggest a correspondence between SWR types and different cognitive functions. In particular, there is no evidence to suggest that some SWRs are better suited to consolidation than others. Indeed, slice electro-physiology and modelling indicate that SWRs with forward and reverse replays may equally support synaptic strengthening or downscaling and could therefore both subserve consolidation $9,12,112,198$.

We therefore propose the working hypothesis that each SWR simultaneously retrieves a memory and, in doing so, drives that memory's consolidation (fig. 3). This hypothesis is consistent with recent work indicating that memory retrieval shares many molecular mechanisms with consolidation, including protein synthesis and NMDA receptor-mediated AMPA receptor trafficking ${ }^{52,199,200}$. Furthermore, the proposal that the two processes typically occur together to support normal behaviour might explain findings in the reconsolidation field that retrieval with blockade of synaptic strengthening (that is, consolidation) degrades a memory ${ }^{201-206}$. Such a relationship would also guarantee the adaptive solution of strengthening and transformation through consolidation of regularly retrieved and used memories. This notion is similar to the old idea that each act of retrieval forms a new, composite memory for the retrieved information in its current context to extract generalities ${ }^{4,59}$.

What, then, would happen when SWRs include activity representing partially or fully novel sequences? Specifically, is there a mechanism by which these are prevented from being consolidated? Alternatively, it is possible that they are consolidated but in such a way as to 
be differentiable from memories of experience ${ }^{207,208}$. Such consolidation of novel — but realistic - sequences is a potentially adaptive method of creating and maintaining a cognitive map of the environment ${ }^{6,9,81,209}$.

\section{Conclusions}

The evidence suggests that SWR activity is a general mechanism for the retrieval of information gained through past experience that provides an adaptive advantage to future behaviour on multiple timescales - in decision-making and planning in the short term and in consolidation, facilitating future instances of retrieval and use in the long term. We hypothesize that any given SWR can mediate retrieval for decision-making, planning, imagination or recollection, depending on behavioural demands and internal brain states (for example, following reward $\left.{ }^{135}\right)^{101}$. Although these different demands and brain states probably induce different types of SWR event (for example, forward versus reverse or centrifugal versus centripetal replays (FIG. 2)) for different immediate uses, our working hypothesis is that, in every case, the retrieved activity pattern also contributes to a consolidation process (FIG. 3). Although it is less clear what the immediate uses of retrieval in sleep are ${ }^{83,18}$, we would expect the same multiplicity of function in that state. In this formulation, the SWR is a general mechanism for ongoing consolidation and retrieval processes that support a memory at every point following its encoding.

An ideal test of this hypothesis would isolate specific periods during behaviour when retrieval or consolidation are known to occur and, within these periods, classify subtypes of SWR on the basis of their replay content. Observation and disruption of this activity 210,211 with concordant measurement of established synaptic consolidation processes and neural activity in other brain regions would test whether there is a specific subset of SWRs that functions in consolidation. Although emerging similarities between retrieval and consolidation have been noted previously, here we have found it valuable to discuss them explicitly and in relation to the SWR as a potentially shared mechanism. Further study of SWR activity has the potential to refine these memory concepts and uncover their mechanisms.

\section{Acknowledgements}

The authors thank J. Andreas, A. E. Comrie, T. Davidson, J. Guidera, T. H. Joo, K. Kay, H. Liang, B. P. Nachman and all other members of the Frank Lab for helpful discussion and close reading of sections of this text. The authors apologize to those whose work was not cited because of limited space. This work was supported by National Institue of Mental Health (NIMH) award number F30MH115582 (H.R.J.), National Institute of General Medical Sciences Medical Scientist Training Program grant \#T32GM007618 (H.R.J.), NIMH grant R01 MH10517 (L.M.F.) and the Howard Hughes Medical Institute (L.M.F.). The content is solely the responsibility of the authors and does not necessarily represent the official views of the National Institutes of Health.

\section{References}

1. Cohen NJ \& Eichenbaum H Memory, Amnesia, and the Hippocampal System (MIT Press, 1993).

2. Squire LR \& Alvarez P Retrograde amnesia and memory consolidation: a neurobiological perspective. Curr. Opin. Neurobiol 5, 169-177 (1995). [PubMed: 7620304]

3. Kandel ER, Dudai Y \& Mayford MR The molecular and systems biology of memory. Cell 157, 163-186 (2014). [PubMed: 24679534] 
4. Schacter DL Forgotten Ideas, Neglected Pioneers: Richard Semon and the Story of Memory (Taylor \& Francis, 2012).

5. Vanderwolf $\mathrm{CH}$ Hippocampal electrical activity and voluntary movement in the rat. Electroencephalogr. Clin. Neurophysiol 26, 407-418 (1969). [PubMed: 4183562]

6. O’Keefe J \& Nadel L The Hippocampus as a Cognitive Map (Oxford Univ. Press, 1978).

7. Kay K \& Frank LM Three brain states in the hippocampus and cortex. Hippocampus 10.1002/hipo. 22956 (2018).

8. Buzsaki G Hippocampal sharp wave-ripple:a cognitive biomarker for episodic memory and planning. Hippocampus 25, 1073-1188 (2015). [PubMed: 26135716] This complete, in-depth review covers, among other topics, the physiology of the SWR and its potential functions in health and disease as well as a historical account of the discovery of replay.

9. Foster DJ Replay comes of age. Annu. Rev. Neurosci 40, 581-602 (2017). [PubMed: 28772098]

10. Atherton LA, Dupret D \& Mellor JR Memory trace replay: the shaping of memory consolidation by neuromodulation. Trends Neurosci. 38, 560-570 (2015). [PubMed: 26275935]

11. Tang W \& Jadhav SP Sharp-wave ripples as a signature of hippocampal-prefrontal reactivation for memory during sleep and waking states. Neurobiol. Learn. Mem 10.1016/j.nlm.2018.01.002 (2018).

12. Pfeiffer BE The content of hippocampal "replay". Hippocampus 10.1002/hipo.22824 (2017).

13. Olafsdottir HF, Bush D \& Barry C The role of hippocampal replay in memory and planning. Curr. Biol 28, R37-R50 (2018). [PubMed: 29316421]

14. Rothschild G The transformation of multi-sensory experiences into memories during sleep. Neurobiol. Learn. Mem 10.1016/j.nlm.2018.03.019 (2018).

15. Carr MF, Jadhav SP \& Frank LM Hippocampal replay in the awake state: a potential substrate for memory consolidation and retrieval. Nat. Neurosci 14, 147-153 (2011). [PubMed: 21270783]

16. Yu JY \& Frank LM Hippocampal-cortical interaction in decision making. Neurobiol. Learn. Mem 117C, 34-41 (2015).

17. Girardeau G \& Zugaro M Hippocampal ripples and memory consolidation. Curr. Opin. Neurobiol 21, 452-459 (2011). [PubMed: 21371881]

18. Roumis DK \& Frank LM Hippocampal sharp-wave ripples in waking and sleeping states. Curr. Opin. Neurobiol 35, 6-12 (2015). [PubMed: 26011627]

19. Squire LR Mechanisms of memory. Science 232, 1612-1619 (1986). [PubMed: 3086978]

20. Scoville WB \& Milner B Loss of recent memory after bilateral hippocampal lesions. J. Neurol. Neurosurg. Psychiatry 20, 11-21 (1957). [PubMed: 13406589]

21. Cohen NJ, Poldrack RA \& Eichenbaum H Memory for items and memory for relations in the procedural/declarative memory framework. Memory 5, 131-178 (1997). [PubMed: 9156097]

22. Tulving E Episodic memory: from mind to brain. Annu. Rev. Psychol 53, 1-25 (2002). [PubMed: 11752477]

23. Eichenbaum H, Dudchenko P, Wood E, Shapiro M \& Tanila H The hippocampus, memory, and place cells: is it spatial memory or a memory space? Neuron 37 23, 209-226 (1999).

24. Wirth $\mathrm{S}$ et al. Single neurons in the monkey hippocampus and learning of new associations. Science 300, 1578-1581 (2003). [PubMed: 12791995]

25 . Wirth $\mathrm{S}$ et al. Trial outcome and associative learning signals in the monkey hippocampus. Neuron 61, 930-940 (2009). [PubMed: 19324001]

26. Rutishauser U, Mamelak AN \& Schuman EM Single-trial learning of novel stimuli by individual neurons of the human hippocampus-amygdala complex. Neuron 49, 805-813 (2006). [PubMed: 16543129]

27. Rutishauser U, Ross IB, Mamelak AN \& Schuman EM Human memory strength is predicted by theta-frequency phase-locking of single neurons. Nature 464, 903-907 (2010). [PubMed: 20336071]

28. Winson J Loss of hippocampal theta rhythm results in spatial memory deficit in the rat. Science 201,160-163 (1978). [PubMed: 663646] 
29. Hasselmo ME, Bodelon C \& Wyble BPA proposed function for hippocampal theta rhythm: separate phases of encoding and retrieval enhance reversal of prior learning. Neural Comput. 14, 793-817 (2002). [PubMed: 11936962]

30. Spellman T et al. Hippocampal-prefrontal input supports spatial encoding in working memory. Nature 522, 309-314 (2015). [PubMed: 26053122]

31. Frankland PW \& Bontempi B The organization of recent and remote memories. Nat. Rev. Neurosci 6, 119-130 (2005). [PubMed: 15685217]

32. Kim JJ \& Fanselow MS Modality-specific retrograde amnesia of fear. Science 256, 675-677 (1992). [PubMed: 1585183]

33. Dudai Y The restless engram: consolidations never end. Annu. Rev. Neurosci 35, 227-247 (2012). [PubMed: 22443508]

34. Dudai Y, Roediger HL 3rd. \& Tulving E in Science of Memory: Concepts(eds Dudai Y, Roediger HL 3rd. \& Fitzpatrick SM) 1-9 (Oxford Univ. Press, 2007).This book selects and defines memory concepts such as retrieval and consolidation. It argues that concept definitions are valuable to the study of memory because they enable communication between levels of study within neuroscience and across disciplines such as psychology and physiology and they identify elemental problems in the field.

35. Dudai Y \& Carruthers M The Janus face of Mnemosyne. Nature 434, 567(2005). [PubMed: 15800602]

36. Morris RG, Garrud P, Rawlins JN \& O'Keefe J Place navigation impaired in rats with hippocampal lesions. Nature 297, 681-683 (1982). [PubMed: 7088155]

37. Jutras MJ \& Buffalo EA Recognition memory signals in the macaque hippocampus. Proc. Natl Acad. Sci. USA 107, 401-406 (2010). [PubMed: 20018683]

38. Winocur G, Moscovitch M \& Bontempi B Memory formation and long-term retention in humans and animals: convergence towards a transformation account of hippocampal-neocortical interactions. Neuropsychologia 48, 2339-2356 (2010). [PubMed: 20430044]

39. Nadel L, Samsonovich A, Ryan L \& Moscovitch M Multiple trace theory of human memory: computational, neuroimaging, and neuropsychological results. Hippocampus 10, 352-368 (2000). [PubMed: 10985275]

40. Hassabis D, Kumaran D \& Maguire EA Using imagination to understand the neural basis of episodic memory. J. Neurosci 27, 14365-14374 (2007). [PubMed: 18160644]

41. Hassabis D, Kumaran D, Vann SD \& Maguire EA Patients with hippocampal amnesia cannot imagine new experiences. Proc. Natl Acad. Sci. USA 104, 1726-1731 (2007). [PubMed: 17229836]

42. Schacter DL et al. The future of memory: remembering, imagining, and the brain. Neuron 76,677694 (2012). [PubMed: 23177955]

43. Suzuki WA \& Eichenbaum H The neurophysiology of memory. Ann. NY Acad. Sci 911, 175-191 (2000). [PubMed: 10911874]

44. Squire LR \& Zola-Morgan S The medial temporal lobe memory system. Science 253, 1380-1386 (1991). [PubMed: 1896849]

45. Riedel $\mathrm{G}$ et al. Reversible neural inactivation reveals hippocampal participation in several memory processes. Nat. Neurosci 2, 898-905 (1999). [PubMed: 10491611]

46. Anagnostaras SG, Maren S \& Fanselow MS Temporally graded retrograde amnesia of contextual fear after hippocampal damage in rats: within-subjects examination. J. Neurosci 19, 1106-1114 (1999). [PubMed: 9920672]

47. Sekeres MJ, Winocur G \& Moscovitch M The hippocampus and related neocortical structures in memory transformation. Neurosci. Lett 680, 39-53 (2018). [PubMed: 29733974]

48. Dudai Y The neurobiology of consolidations, or, how stable is the engram? Annu. Rev. Psychol 55, 51-86 (2004). [PubMed: 14744210]

49. Dudai Y, Karni A \& Born J The consolidation and transformation of memory. Neuron 88, 20-32 (2015). [PubMed: 26447570]

50. Lisman J, Cooper K, Sehgal M \& Silva AJ Memory formation depends on both synapse-specific modifications of synaptic strength and cell-specific increases in excitability. Nat. Neurosci 21, 309-314 (2018). [PubMed: 29434376] 
51. Poo MM et al. What is memory? The present state of the engram. BMC Biol. 14, 40(2016). [PubMed: 27197636]

52. Ben-Yakov A, Dudai Y \& Mayford MR Memory retrieval in mice and men. Cold Spring Harb. Perspect. Biol 7, a021790(2015). [PubMed: 26438596]

53. McGaugh JL Memory—a century of consolidation. Science 287, 248-251 (2000). [PubMed: 10634773]

54. Squire LR, Genzel L, Wixted JT \& Morris RG Memory consolidation. Cold Spring Harb. Perspect. Biol 7, a021766(2015). [PubMed: 26238360]

55. Sutherland RJ et al. Retrograde amnesia after hippocampal damage: recent versus remote memories in two tasks. Hippocampus 11, 27-42 (2001). [PubMed: 11261770]

56. Martin SJ, de Hoz L \& Morris RG Retrograde amnesia: neither partial nor complete hippocampal lesions in rats result in preferential sparing of remote spatial memory, even after reminding. Neuropsychologia 43, 609-624 (2005). [PubMed: 15716151]

57. Born J \& Wilhelm I System consolidation of memory during sleep. Psychol. Res 76, 192-203 (2012). [PubMed: 21541757]

58. Josselyn SA \& Frankland PW Memory allocation: mechanisms and function. Annu. Rev. Neurosci 41, 389-413 (2018). [PubMed: 29709212]

59. Semon RW Mnemic Psychology (George Allen \& Unwin, 1923).

60. Buzsaki G, Leung LW \& Vanderwolf CH Cellular bases of hippocampal EEG in the behaving rat. Brain Res. 287, 139-171 (1983). [PubMed: 6357356]

61. Buzsaki G Hippocampal sharp waves - their origin and significance. Brain Res. 398, 242-252 (1986). [PubMed: 3026567]

62. Sullivan D et al. Relationships between hippocampal sharp waves, ripples, and fast gamma oscillation: influence of dentate and entorhinal cortical activity. J. Neurosci 31, 8605-8616 (2011). [PubMed: 21653864]

63. Suzuki SS \& Smith GK Spontaneous EEG spikes in the normal hippocampus. V. Effects of ether, urethane, pentobarbital, atropine, diazepam and bicuculline. Electroencephalogr. Clin. Neurophysiol 70, 84-95 (1988). [PubMed: 2455634]

64. Ylinen A et al. Sharp wave-associated high-frequency oscillation $(200 \mathrm{~Hz})$ in the intact hippocampus:network and intracellular mechanisms. J. Neurosci 15, 30-46 (1995). [PubMed: 7823136]

65. Oliva A, Fernandez-Ruiz A, Buzsaki G \& Berenyi A Role of hippocampal CA2 region in triggering sharp-wave ripples. Neuron 91, 1342-1355 (2016). [PubMed: 27593179]

66. Sasaki $\mathrm{T}$ et al. Dentate network activity is necessary for spatial working memory by supporting CA3 sharp-wave ripple generation and prospective firing of CA3 neurons. Nat. Neurosci 21, 258269 (2018). [PubMed: 29335604]

67. Amaral DG \& Witter MP The three-dimensional organization of the hippocampal formation: a review of anatomical data. Neuroscience 31, 571-591 (1989). [PubMed: 2687721]

68. Li XG, Somogyi P, Ylinen A \& Buzsaki G The hippocampal CA3 network: an in vivo intracellular labeling study. J. Comp. Neurol 339, 181-208 (1994). [PubMed: 8300905]

69. Valero $\mathrm{M}$ et al. Mechanisms for selective single-cell reactivation during offline sharp-wave ripples and their distortion by fast ripples. Neuron 94, 1234-1247.e7 (2017). [PubMed: 28641116]

70. Suzuki SS \& Smith GK Spontaneous EEG spikes in the normal hippocampus. I. Behavioral correlates, laminar profiles and bilateral synchrony. Electroencephalogr. Clin. Neurophysiol 67, 348-359 (1987). [PubMed: 2441970]

71. Jouvet M, Michel F \& Courjon J Electric activity of the rhinencephalon during sleep in cats. C. R. Seances Soc. Biol. Fil 153, 101-105 (1959). [PubMed: 13663367]

72. Buzsaki G, Horvath Z, Urioste R, Hetke J \& Wise K High-frequency network oscillation in the hippocampus. Science 256, 1025-1027 (1992). [PubMed: 1589772]

73. English DF et al. Excitation and inhibition compete to control spiking during hippocampal ripples: intracellular study in behaving mice. J. Neurosci 34, 16509-16517 (2014). [PubMed: 25471587]

74. Stark E et al. Pyramidal cell-interneuron interactions underlie hippocampal ripple oscillations. Neuron 83, 467-480 (2014). [PubMed: 25033186] 
75. Csicsvari J, Hirase H, Czurko A, Mamiya A \& Buzsaki G Fast network oscillations in the hippocampal CA1 region of the behaving rat.J. Neurosci 19, RC20(1999). [PubMed: 10436076]

76. Cheng S \& Frank LM New experiences enhance coordinated neural activity in the hippocampus. Neuron 57, 303-313 (2008). [PubMed: 18215626]

77. Pfeiffer BE \& Foster DJ Hippocampal place-cell sequences depict future paths to remembered goals. Nature 497, 74-79 (2013). [PubMed: 23594744] This compelling study identifies novel replay sequences starting from a rat's current location and progressing towards a known goal location. This finding is one of the strongest pieces of evidence in support of a role for SWR replay in planning to guide immediately upcoming behaviour.

78. Buzsaki G Two-stage model of memory trace formation: a role for "noisy" brain states. Neuroscience 31, 551-570 (1989). [PubMed: 2687720]

79. Thorndike EL \& Columbia U The Fundamentals of Learning. (Teachers College, Columbia Univ., 1932).

80. Redish AD Vicarious trial and error. Nat. Rev. Neurosci 17, 147-159 (2016). [PubMed: 26891625]

81. Papale AE, Zielinski MC, Frank LM, Jadhav SP\& Redish, A. D. Interplay between hippocampal sharp-wave-ripple events and vicarious trial and error behaviors in decision making. Neuron 92, 975-982 (2016). [PubMed: 27866796]

82. Speer ME, Bhanji JP \& Delgado MR Savoring the past: positive memories evoke value representations in the striatum. Neuron 84, 847-856 (2014). [PubMed: 25451197]

83. Wagner U, Gais S, Haider H, Verleger R \& Born J Sleep inspires insight. Nature 427, 352-355 (2004). [PubMed: 14737168]

84. O'Neill J, Senior T \& Csicsvari J Place-selective firing of CA1 pyramidal cells during sharp wave/ ripple network patterns in exploratory behavior. Neuron 49, 143-155 (2006). [PubMed: 16387646]

85. Wang DV et al. Mesopontine median raphe regulates hippocampal ripple oscillation and memory consolidation. Nat. Neurosci 18, 728-735 (2015). [PubMed: 25867120]

86. Vandecasteele $\mathrm{M}$ et al. Optogenetic activation of septal cholinergic neurons suppresses sharp wave ripples and enhances theta oscillations in the hippocampus. Proc. Natl Acad. Sci. USA 111,1353513540 (2014). [PubMed: 25197052]

87. Giovannini MG et al. Effects of novelty and habituation on acetylcholine, GABA, and glutamate release from the frontal cortex and hippocampus of freely moving rats. Neuroscience 106, 43-53 (2001). [PubMed: 11564415]

88. Liu Y, McAfee SS \& Heck DH Hippocampal sharp-wave ripples in awake mice are entrained by respiration. Sci. Rep 7, 8950(2017). [PubMed: 28827599]

89. O’Neill J, Senior TJ, Allen K, Huxter JR \& Csicsvari J Reactivation of experience-dependent cell assembly patterns in the hippocampus. Nat. Neurosci 11, 209-215 (2008). [PubMed: 18193040]

90. Karlsson MP \& Frank LM Network dynamics underlying the formation of sparse, informative representations in the hippocampus. J. Neurosci 28, 14271-14281 (2008). [PubMed: 19109508]

91. Eschenko O, Ramadan W, Molle M, Born J \& Sara SJ Sustained increase in hippocampal sharpwave ripple activity during slow-wave sleep after learning. Learn. Mem 15, 222-228 (2008). [PubMed: 18385477]

92. Jackson JC, Johnson A \& Redish AD Hippocampal sharp waves and reactivation during awake states depend on repeated sequential experience. J. Neurosci 26, 12415-12426 (2006). [PubMed: 17135403]

93. Singer AC \& Frank LM Rewarded outcomes enhance reactivation of experience in the hippocampus. Neuron 64, 910-921 (2009). [PubMed: 20064396]

94. Foster DJ \& Wilson MA Reverse replay of behavioural sequences in hippocampal place cells during the awake state. Nature 440, 680-683 (2006). [PubMed: 16474382] This study is the first description of reverse replay and is the first to propose that reverse replay functions in credit assignment.

95. Marr D Simple memory: a theory for archicortex. Phil. Trans. R. Soc. Lond. B 262, 23-81 (1971). [PubMed: 4399412]

96. O'Reilly RC \& Rudy JW Computational principles of learning in the neocortex and hippocampus. Hippocampus 10, 389-397 (2000). [PubMed: 10985278] 
97. Girardeau G, Benchenane K, Wiener SI, Buzsaki G \& Zugaro MB Selective suppression of hippocampal ripples impairs spatial memory. Nature Neurosci. 12, 1222-1223 (2009). [PubMed: 19749750]

98. Ego-Stengel V \& Wilson MA Disruption of ripple-associated hippocampal activity during rest impairs spatial learning in the rat. Hippocampus 20, 1-10 (2010). [PubMed: 19816984]

99. Nakashiba T, Buhl DL, McHugh TJ \& Tonegawa S Hippocampal CA3 output is crucial for rippleassociated reactivation and consolidation of memory. Neuron 62, 781-787 (2009). [PubMed: 19555647]

100. Novitskaya Y, Sara SJ, Logothetis NK \& Eschenko O Ripple-triggered stimulation of the locus coeruleus during post-learning sleep disrupts ripple/spindle coupling and impairs memory consolidation. Learn. Mem 23, 238-248 (2016). [PubMed: 27084931]

101. Girardeau G, Cei A \& Zugaro M Learning-induced plasticity regulates hippocampal sharp waveripple drive. J. Neurosci 34, 5176-5183 (2014). [PubMed: 24719097] This article provides the first demonstration that SWRs during post-experience sleep are necessary for a normal learning rate in a spatial memory task.

102. Maingret N, Girardeau G, Todorova R, Goutierre M \& Zugaro M Hippocampo-cortical coupling mediates memory consolidation during sleep. Nat. Neurosci19, 959-964 (2016). [PubMed: 27182818] This paper presents the first gain-of-function study of hippocampal-cortical coordination during the SWR. Electrical stimulation that enhanced the coordination between SWRs and cortical delta waves and spindles during post-experience sleep improved subsequent memory performance.

103. Jadhav SP, Kemere C, German PW \& Frank LM Awake hippocampal sharp-wave ripples support spatial memory. Science 336, 1454-1458 (2012). [PubMed: 22555434] This article presents the first study to demonstrate the necessity of awake SWRs in learning. It uses electrical stimulation to truncate SWRs during a spatial working memory task.

104. Nokia MS, Mikkonen JE, Penttonen M \& Wikgren J Disrupting neural activity related to awakestate sharp wave-ripple complexes prevents hippocampal learning. Front. Behav. Neurosci 6, 84(2012). [PubMed: 23316148]

105. Jadhav SP \& Frank LM in Time, Space and Memory in the Hippocampal Formation (eds Derdikman D \& Knierim JJ) 351-371 (Space, 2014).

106. Nokia MS, Penttonen M \& Wikgren J Hippocampal ripple-contingent training accelerates trace eyeblink conditioning and retards extinction in rabbits. J. Neurosci 30, 11486-11492 (2010). [PubMed: 20739570]

107. O'Keefe J \& Dostrovsky J The hippocampus as a spatial map. Preliminary evidence from unit activity in the freely-moving rat. Brain Res. 34, 171-175 (1971). [PubMed: 5124915]

108. Moser M-B, Rowland DC \& Moser EI Place cells, grid cells, and memory. Cold Spring Harb. Perspect. Biol 7, a021808(2015). [PubMed: 25646382]

109. Roux L, Hu B, Eichler R, Stark E \& Buzsaki G Sharp wave ripples during learning stabilize the hippocampal spatial map. Nat. Neurosci 20, 845-853 (2017). [PubMed: 28394323] This important study links awake SWR activity to learning in the form of place cell stabilization. Optogenetically silencing a subset of CA1 cells during awake SWRs led to place field remapping specifically for this subset.

110. van de Ven GM, Trouche S, McNamara CG, Allen K \& Dupret D Hippocampal offline reactivation consolidates recently formed cell assembly patterns during sharp wave-ripples. Neuron 92, 968-974 (2016). [PubMed: 27840002]

111. Kovacs KA et al. Optogenetically blocking sharp wave ripple events in sleep does not interfere with the formation of stable spatial representation in the CA1 area of the hippocampus. PLOS ONE 11, e0164675(2016). [PubMed: 27760158]

112. Sadowski JH, Jones MW \& Mellor JR Sharp-wave ripples orchestrate the induction of synaptic plasticity during reactivation of place cell firing patterns in the hippocampus. Cell Rep. 14, 19161929 (2016). [PubMed: 26904941]

113. Behrens CJ, van den Boom LP, de HL, Friedman A \& Heinemann U Induction of sharp waveripple complexes in vitro and reorganization of hippocampal networks. Nat. Neurosci 8, 15601567 (2005). [PubMed: 16222227] 
114. Norimoto H et al. Hippocampal ripples down-regulate synapses. Science 359, 1524-1527 (2018). [PubMed: 29439023] This study links in vivo SWR activity in mice to change at the synaptic level, reporting that optogenetic silencing of SWRs during sleep impairs learning and maintains synaptic weights that are otherwise observed to be downregulated.

115. Lubenov EV \& Siapas AG Decoupling through synchrony in neuronal circuits with propagation delays. Neuron 58, 118-131 (2008). [PubMed: 18400168]

116. Tononi G \& Cirelli C Sleep function and synaptic homeostasis. Sleep Med. Rev 10, 49-62 (2006). [PubMed: 16376591]

117. Tonegawa S, Liu X, Ramirez S \& Redondo R Memory engram cells have come of age. Neuron 87,918-931 (2015). [PubMed: 26335640]

118. Pavlides C \& Winson J Influences of hippocampal place cell firing in the awake state on the activity of these cells during subsequent sleep episodes. J. Neurosci 9, 2907-2918 (1989). [PubMed: 2769370]

119. Wilson MA \& McNaughton BL Reactivation of hippocampal ensemble memories during sleep.Science 265, 676-679 (1994). [PubMed: 8036517]

120. Kudrimoti HS, Barnes CA \& McNaughton BL Reactivation of hippocampal cell assemblies: effects of behavioral state, experience, and EEG dynamics. J. Neurosci 19, 4090-4101 (1999). [PubMed: 10234037]

121. Dupret D, O’Neill J, Pleydell-Bouverie B \& Csicsvari J The reorganization and reactivation of hippocampal maps predict spatial memory performance. Nat. Neurosci 13, 995-1002 (2010). [PubMed: 20639874] This elegant study finds that awake SWRs with activity specifically associated with goal locations predict subsequent memory performance and that this effect is dependent on the NMDA receptor.

122. Yu JY et al. Distinct hippocampal-cortical memory representations for experiences associated with movement versus immobility. eLife 6, e27621(2017). [PubMed: 28826483]

123. Lee AK \& Wilson MA Memory of sequential experience in the hippocampus during slow wave sleep. Neuron 36, 1183-1194 (2002). [PubMed: 12495631]

124. Diba K \& Buzsaki G Forward and reverse hippocampal place-cell sequences during ripples. Nat. Neurosci 10, 1241-1242 (2007). [PubMed: 17828259]

125. Karlsson MP \& Frank LM Awake replay of remote experiences in the hippocampus. Nat. Neurosci 12, 913-918 (2009). [PubMed: 19525943] This study is the first to describe awake replay of remote experiences, which occurs just as frequently as local replay. It demonstrates that replay content is not necessarily triggered by specific sensory inputs in the local environment and introduces the possibility of a retrieval or awake consolidation function for the awake SWR.

126. Gupta AS, van der Meer MA, Touretzky DS \& Redish AD Hippocampal replay is not a simple function of experience. Neuron 65, 695-705 (2010). [PubMed: 20223204] This article presents the first description of novel replay sequences. Replay of a part of the environment was more frequent when it had not been recently visited, demonstrating that replay is not a simple function of recent experience.

127. Davidson TJ, Kloosterman F \& Wilson MA Hippocampal replay of extended experience. Neuron 63, 497-507 (2009). [PubMed: 19709631] This study identifies extended replay sequences spanning multiple SWRs occurring in succession. It demonstrates that replay progresses at a characteristic speed and indicates chains of SWRs as a potential mechanism for the storage and use of extended experience.

128. Wu X \& Foster DJ Hippocampal replay captures the unique topological structure of a novel environment. J. Neurosci 34, 6459-6469 (2014). [PubMed: 24806672]

129. Tang W, Shin JD, Frank LM \& Jadhav SP Hippocampal-prefrontal reactivation during learning is stronger in awake compared with sleep states. J. Neurosci 37, 11789-11805 (2017). [PubMed: 29089440]

130. Ji D \& Wilson MA Coordinated memory replay in the visual cortex and hippocampus during sleep. Nat. Neurosci 10, 100-107 (2007). [PubMed: 17173043]

131. Jackson J \& Redish AD Network dynamics of hippocampal cell-assemblies resemble multiple spatial maps within single tasks. Hippocampus 17, 1209-1229 (2007). [PubMed: 17764083] 
132. Olafsdottir HF, Carpenter F \& Barry C Task demands predict a dynamic switch in the content of awake hippocampal replay. Neuron 96, 925-935.e6 (2017). [PubMed: 29056296]

133. McNaughton BL, Barnes CA \& O'Keefe J The contributions of position, direction, and velocity to single unit activity in the hippocampus of freely-moving rats. Exp. Brain Res. 52, 41-49 (1983). [PubMed: 6628596]

134. Frank LM, Stanley GB \& Brown EN Hippocampal plasticity across multiple days of exposure to novel environments. J. Neurosci 24, 7681-7689 (2004). [PubMed: 15342735]

135. Ambrose RE, Pfeiffer BE \& Foster DJ Reverse replay of hippocampal place cells is uniquely modulated by changing reward. Neuron 91, 1124-1136 (2016). [PubMed: 27568518] This study finds modulation of SWR rate by reward that is accounted for specifically by modulation of reverse replay, indicating a functional difference between reverse and forward replay events. Specifically, this study suggests that reverse replay functions in credit assignment.

136. Clayton NS, Bussey TJ \& Dickinson A Can animals recall the past and plan for the future? Nat. Rev. Neurosci 4, 685-691 (2003). [PubMed: 12894243]

137. Panoz-Brown D et al. Replay of episodic memories in the rat. Curr. Biol28, 1628-1634.e7 (2018). [PubMed: 29754898]

138. Singer AC, Carr MF, Karlsson MP \& Frank LM Hippocampal SWR activity predicts correct decisions during the initial learning of an alternation task.Neuron 77, 1163-1173 (2013). [PubMed: 23522050]

139. Wu CT, Haggerty D, Kemere C \& Ji D Hippocampal awake replay in fear memory retrieval. Nat. Neurosci 20, 571-580 (2017). [PubMed: 28218916]

140. Wikenheiser AM \& Redish AD The balance of forward and backward hippocampal sequences shifts across behavioral states. Hippocampus 23, 22-29 (2013). [PubMed: 22736562]

141. Buckner RL The role of the hippocampus in prediction and imagination. Annu. Rev. Psychol 61, 27-48 (2010). [PubMed: 19958178]

142. Dragoi G \& Tonegawa S Selection of preconfigured cell assemblies for representation of novel spatial experiences. Phil. Trans. R. Soc. B 369, 20120522(2014). [PubMed: 24366134]

143. Dragoi G \& Tonegawa S Preplay of future place cell sequences by hippocampal cellular assemblies. Nature 469, 397-401 (2011). [PubMed: 21179088]

144. Grosmark AD \& Buzsaki G Diversity in neural firing dynamics supports both rigid and learned hippocampal sequences. Science 351, 1440-1443 (2016). [PubMed: 27013730]

145. Silva D, Feng T \& Foster DJ Trajectory events across hippocampal place cells require previous experience. Nat. Neurosci 18, 1772-1779 (2015). [PubMed: 26502260]

146. Schwindel CD \& McNaughton BL Hippocampal-cortical interactions and the dynamics of memory trace reactivation. Prog. Brain Res. 193, 163-177 (2011). [PubMed: 21854962]

147. Rissman J \& Wagner AD Distributed representations in memory: insights from functional brain imaging.Annu. Rev. Psychol63, 101-128 (2012). [PubMed: 21943171]

148. Rajasethupathy $\mathrm{P}$ et al. Projections from neocortex mediate top-down control of memory retrieval. Nature 526, 653-659 (2015). [PubMed: 26436451]

149. Siapas AG \& Wilson MA Coordinated interactions between hippocampal ripples and cortical spindles during slow-wave sleep. Neuron 21, 1123-1128 (1998). [PubMed: 9856467]

150. Staresina BP et al. Hierarchical nesting of slow oscillations, spindles and ripples in the human hippocampus during sleep. Nat. Neurosci 18, 1679-1686 (2015). [PubMed: 26389842]

151. Penttonen M, Kamondi A, Sik A, Acsady L \& Buzsaki G Feed-forward and feed-back activation of the dentate gyrus in vivo during dentate spikes and sharp wave bursts. Hippocampus 7, 437450 (1997). [PubMed: 9287083]

152. Bragin A, Jando G, Nadasdy Z, van Landeghem M\& Buzsaki, G. Dentate EEG spikes and associated interneuronal population bursts in the hippocampal hilar region of the rat. J. Neurophysiol 73,1691-1705 (1995). [PubMed: 7643175]

153. O’Neill J, Boccara CN, Stella F, Schoenenberger P \& Csicsvari J Superficial layers of the medial entorhinal cortex replay independently of the hippocampus.Science 355, 184-188 (2017). [PubMed: 28082591] 
154. Chrobak JJ \& Buzsaki G Selective activation of deep layer (V-VI) retrohippocampal cortical neurons during hippocampal sharp waves in the behaving rat.J. Neurosci 14, 6160-6170 (1994). [PubMed: 7931570]

155. Chrobak JJ \& Buzsaki G High-frequency oscillations in the output networks of the hippocampalentorhinal axis of the freely behaving rat. J. Neurosci 16,3056-3066 (1996). [PubMed: 8622135]

156. Olafsdottir HF, Carpenter F \& Barry C Coordinated grid and place cell replay during rest. Nat. Neurosci19, 792-794 (2016). [PubMed: 27089021]

157. Chung JE et al. A polymer probe-based system for high density, long-lasting electrophysiological recordings across distributed neuronal circuits. Preprint at bioRxiv 10.1101/242693 (2018).

158. Wierzynski CM, Lubenov EV, Gu M \& Siapas AG State-dependent spike-timing relationships between hippocampal and prefrontal circuits during sleep. Neuron 61, 587-596 (2009). [PubMed: 19249278]

159. Jadhav SP, Rothschild G, Roumis DK \& Frank LM Coordinated excitation and inhibition of prefrontal ensembles during awake hippocampal sharp-wave ripple events. Neuron 90, 113-127 (2016). [PubMed: 26971950] This study identifies a population of PFC neurons with firing rates modulated by awake SWRs. PFC neurons that increase firing rate tend to represent prior experience, whereas those that decrease firing rate are associated with the current location.

160. Remondes M \& Wilson MA Slow-gamma rhythms coordinate cingulate cortical responses to hippocampal sharp-wave ripples during wakefulness. Cell Rep.13, 1327-1335 (2015). [PubMed: 26549454]

161. Wang DV \& Ikemoto S Coordinated interaction between hippocampal sharp-wave ripples and anterior. J.Neurosci 36, 10663-10672 cingulate unit activity. (2016). [PubMed: 27733616]

162. Rothschild G, Eban E \& Frank LM A cortical-hippocampal-cortical loop of information processing during memory consolidation. Nat. Neurosci20, 251-259 (2017). [PubMed: 27941790] This study identifies a cortical-hippocampal-cortical loop of information transmission during sleep.During sleep, delivering sounds that were associated during wake with traversal of specific spatial trajectories biases the content of activity in this loop.

163. Wilber AA, Skelin I, Wu W \& McNaughton BL Laminar organization of encoding and memory reactivation in the parietal cortex. Neuron 95, 1406-1419.e5 (2017). [PubMed: 28910623]

164. Pennartz CM et al. The ventral striatum in off-line processing: ensemble reactivation during sleep and modulation by hippocampal ripples. J. Neurosci 24, 6446-6456 (2004). [PubMed: 15269254]

165. Lansink CS, Goltstein PM, Lankelma JV, McNaughton BL \& Pennartz CM Hippocampus leads ventral striatum in replay of place-reward information. PLOS Biol. 7, e1000173(2009). [PubMed: 19688032]

166. Gomperts SN, Kloosterman F \& Wilson MA VTA neurons coordinate with the hippocampal reactivation of spatial experience. eLife 4, e05360(2015). [PubMed: 26465113]

167. Valdes JL, McNaughton BL \& Fellous JM Offline reactivation of experience-dependent neuronal firing patterns in the rat ventral tegmental area. J. Neurophysiol 114, 1183-1195 (2015). [PubMed: 26108957]

168. Khodagholy D, Gelinas JN \& Buzsaki G Learning-enhanced coupling between ripple oscillations in association cortices and hippocampus. Science 358, 369-372 (2017). [PubMed: 29051381] This study reports ripples in association cortex but not sensory cortex co-incident with hippocampal SWRs, with stronger coupling after learning. This study begins to address the question of which cortical areas, specifically, are involved in systems consolidation.

169. Ribeiro $S$ et al. Long-lasting novelty-induced neuronal reverberation during slow-wave sleep in multiple forebrain areas. PLOS Biol. 2, E24(2004). [PubMed: 14737198]

170. Logothetis NK et al. Hippocampal-cortical interaction during periods of subcortical silence. Nature 491, 547-553 (2012). [PubMed: 23172213]

171. Yu JY, Liu DF, Loback A, Grossrubatscher I \& Frank LM Specific hippocampal representations are linked to generalized cortical representations in memory. Preprint at bioRxiv 10.1101/207142 (2017).

172. Battaglia FP, Sutherland GR \& McNaughton BL Hippocampal sharp wave bursts coincide with neocortical "up-state" transitions. Learn. Mem 11, 697-704 (2004). [PubMed: 15576887] 
173. Sirota A, Csicsvari J, Buhl D \& Buzsaki G Communication between neocortex and hippocampus during sleep in rodents. Proc. Natl Acad. Sci. USA 100, 2065-2069 (2003). [PubMed: 12576550]

174. Isomura $\mathrm{Y}$ et al. Integration and segregation of activity in entorhinal-hippocampal subregions by neocortical slow oscillations. Neuron 52, 871-882 (2006). [PubMed: 17145507]

175. Peyrache A, Khamassi M, Benchenane K,Wiener SI \& Battaglia FP Replay of rule-learning related neural patterns in the prefrontal cortex during sleep. Nat. Neurosci 12, 919-926 (2009). [PubMed: 19483687]

176. Bendor D \& Wilson MA Biasing the content of hippocampal replay during sleep. Nat. Neurosci 15, 1439-1444 (2012). [PubMed: 22941111]

177. Teyler TJ \& Rudy JW The hippocampal indexing theory and episodic memory: updating the index. Hippocampus 17, 1158-1169 (2007). [PubMed: 17696170]

178. Kay K et al. A hippocampal network for spatial coding during immobility and sleep. Nature 531, 185-190 (2016). [PubMed: 26934224]

179. Colgin LL Rhythms of the hippocampal network. Nat. Rev. Neurosci 17, 239-249 (2016). [PubMed: 26961163]

180. Dragoi G \& Buzsaki G Temporal encoding of place sequences by hippocampal cell assemblies. Neuron 50, 145-157 (2006). [PubMed: 16600862]

181. Wikenheiser AM \& Redish AD Hippocampal theta sequences reflect current goals. Nat. Neurosci 18, 289-294 (2015). [PubMed: 25559082]

182. Johnson A \& Redish AD Neural ensembles in CA3 transiently encode paths forward of the animal at a decision point. J. Neurosci 27, 12176-12189 (2007). [PubMed: 17989284]

183. Wang Y, Roth Z \& Pastalkova E Synchronized excitability in a network enables generation of internal neuronal sequences. eLife 5, e20697(2016). [PubMed: 27677848]

184. Leonard TK \& Hoffman KL Sharp-wave ripples in primates are enhanced near remembered visual objects. Curr. Biol 27, 257-262 (2017). [PubMed: 28041797]

185. Patel J, Schomburg EW, Berenyi A, Fujisawa S\& Buzsaki, G. Local generation and propagation of ripples along the septotemporal axis of the hippocampus. J. Neurosci 33, 17029-17041 (2013). [PubMed: 24155307]

186. Aronov D, Nevers R \& Tank DW Mapping of a non-spatial dimension by the hippocampalentorhinal circuit. Nature 543, 719-722 (2017). [PubMed: 28358077]

187. Lisman $\mathrm{J}$ et al. Viewpoints: how the hippocampus contributes to memory, navigation and cognition. Nat. Neurosci 20, 1434-1447 (2017). [PubMed: 29073641]

188. Ziv Y et al. Long-term dynamics of CA1 hippocampal place codes. Nat. Neurosci 16, 264-266 (2013). [PubMed: 23396101]

189. Ramirez-Villegas JF, Logothetis NK \& Besserve M Diversity of sharp-wave-ripple LFP signatures reveals differentiated brain-wide dynamical events. Proc. Natl Acad. Sci. USA 112, E6379-E6387 (2015). [PubMed: 26540729]

190. Thorpe S, Fize D \& Marlot C Speed of processing in the human visual system. Nature 381, 520522 (1996). [PubMed: 8632824]

191. Shadlen MN \& Shohamy D Decision making and sequential sampling from memory. Neuron 90 , 927-939 (2016). [PubMed: 27253447]

192. Tse D et al. Schema-dependent gene activation and memory encoding in neocortex. Science 333,891-895 (2011). [PubMed: 21737703]

193. Josselyn SA, Kohler S \& Frankland PW Heroes of the engram. J. Neurosci 37, 4647-4657 (2017). [PubMed: 28469009]

194. O’Neill J, Pleydell-Bouverie B, Dupret D \& Csicsvari J Play it again: reactivation of waking experience and memory. Trends Neurosci. 33, 220-229 (2010). [PubMed: 20207025]

195. Csicsvari J, O’Neill J, Allen K \& Senior T Place-selective firing contributes to the reverse-order reactivation of CA1 pyramidal cells during sharp waves in open-field exploration. Eur. J. Neurosci 26, 704-716 (2007). [PubMed: 17651429]

196. Yamamoto J \& Tonegawa S Direct medial entorhinal cortex input to hippocampal CA1 is crucial for extended quiet awake replay. Neuron 96, 217-227.e4 (2017). [PubMed: 28957670] 
197. Valero M et al. Determinants of different deep and superficial CA1 pyramidal cell dynamics during sharp-wave ripples. Nat. Neurosci 18, 1281-1290 (2015). [PubMed: 26214372]

198. Mishra RK, Kim S, Guzman SJ \& Jonas P Symmetric spike timing-dependent plasticity at CA3CA3 synapses optimizes storage and recall in autoassociative networks. Nat. Commun 7 , 11552(2016). [PubMed: 27174042]

199. Lopez J, Gamache K, Schneider R \& Nader K Memory retrieval requires ongoing protein synthesis and NMDA receptor activity-mediated AMPA receptor trafficking. J. Neurosci 35, 2465-2475 (2015). [PubMed: 25673841]

200. Szapiro G et al. Molecular mechanisms of memory retrieval. Neurochem. Res 27, 1491-1498 (2002). [PubMed: 12512953]

201. Dudai Y Reconsolidation: the advantage of being refocused. Curr. Opin. Neurobiol 16, 174-178 (2006). [PubMed: 16563730]

202. Nader K, Schafe GE \& Le Doux JE Fear memories require protein synthesis in the amygdala for reconsolidation after retrieval. Nature 406, 722-726 (2000). [PubMed: 10963596]

203. Nader K Reconsolidation and the dynamic nature of memory. Cold Spring Harb. Perspect. Biol 7 , a021782(2015). [PubMed: 26354895]

204. Sara SJ Retrieval and reconsolidation: toward a neurobiology of remembering. Learn. Memory 7 , 73-84 (2000).

205. Nader K Memory traces unbound. Trends Neurosci. 26, 65-72 (2003). [PubMed: 12536129]

206. Misanin JR, Miller RR \& Lewis DJ Retrograde amnesia produced by electroconvulsive shock after reactivation of a consolidated memory trace. Science 160, 554-555 (1968). [PubMed: 5689415]

207. Straube B An overview of the neuro-cognitive processes involved in the encoding, consolidation, and retrieval of true and false memories. Behav. Brain Funct. 8, 35(2012). [PubMed: 22827854]

208. Simons JS, Garrison JR \& Johnson MKBrain mechanisms of reality monitoring. Trends Cogn. Sci 21, 462-473 (2017). [PubMed: 28462815]

209. Redish AD Beyond the Cognitive Map: From Place Cells to Episodic Memory (MIT Press, 1999).

210. Ciliberti D \& Kloosterman F Falcon: a highly flexible open-source software for closed-loop neuroscience.J. Neural Eng. 14, 045004(2017). [PubMed: 28548044]

211. Deng X, Liu DF, Karlsson MP, Frank LM \& Eden UT Rapid classification of hippocampal replay content for real-time applications. J. Neurophysiol116, 2221-2235 (2016). [PubMed: 27535369]

212. Kanamori N A spindle-like wave in the cat hippocampus: a novel vigilance level-dependent electrical activity. Brain Res. 334, 180-182 (1985). [PubMed: 3995312]

213. Eguchi K \& Satoh T Relationship between positive sharp wave bursts and unitary discharges in the cat hippocampus during slow wave sleep. Physiol. Behav 40, 497-499 (1987). [PubMed: 3628546]

214. Ulanovsky N \& Moss CF Hippocampal cellular and network activity in freely moving echolocating bats.Nat. Neurosci 10, 224-233 (2007). [PubMed: 17220886]

215. Skaggs WE et al. EEG sharp waves and sparse ensemble unit activity in the macaque hippocampus.J. Neurophysiol 98, 898-910 (2007). [PubMed: 17522177]

216. Leonard TK et al. Sharp wave ripples during visual exploration in the primate hippocampus. J. Neurosci 35, 14771-14782 (2015). [PubMed: 26538648]

217. Axmacher N, Elger CE \& Fell J Ripples in the medial temporal lobe are relevant for human memory consolidation. Brain 131, 1806-1817 (2008). [PubMed: 18503077]

218. Le Van QM et al. Cell type-specific firing during ripple oscillations in the hippocampal formation of humans. J. Neurosci 28, 6104-6110 (2008). [PubMed: 18550752]

219. Bragin A et al. High-frequency oscillations in human brain. Hippocampus 9, 137-142 (1999). [PubMed: 10226774] This study identifies a high-frequency oscillation in the EC and hippocampus of patients with epilepsy as a homologue of the SWR previously identified in rodents, introducing the possibility of their function also in human memory.

220. Shein-Idelson M, Ondracek JM, Liaw HP, Reiter S\& Laurent G Slow waves, sharp waves, ripples, and REM in sleeping dragons. Science 352, 590-595 (2016). [PubMed: 27126045] 
221. Vargas R, Thorsteinsson H \& Karlsson KA Spontaneous neural activity of the anterodorsal lobe and entopeduncular nucleus in adult zebrafish: a putative homologue of hippocampal sharp waves. Behav. Brain Res. 229, 10-20 (2012). [PubMed: 22207154]

222. Staba RJ et al. High-frequency oscillations recorded in human medial temporal lobe during sleep.Ann. Neurol 56, 108-115 (2004). [PubMed: 15236407]

223. Clemens $\mathrm{Z}$ et al. Temporal coupling of parahippocampal ripples, sleep spindles and slow oscillations in humans. Brain 130, 2868-2878 (2007). [PubMed: 17615093]

224. Logothetis NK Neural-event-triggered fMRI of large-scale neural networks. Curr. Opin. Neurobiol 31, 214-222 (2015). [PubMed: 25536423] This study uses ripple-triggered fMRI in monkeys to demonstrate the broad activation of cortical areas and suppression of subcortical areas during the SWR.

225. Kaplan R et al. Hippocampal sharp-wave ripples influence selective activation of the default mode network. Curr. Biol 26, 686-691 (2016). [PubMed: 26898464]

226. Buzsaki G \& Moser EI Memory, navigation and theta rhythm in the hippocampal-entorhinal system. Nat. Neurosci 16, 130-138 (2013). [PubMed: 23354386]

227. Yartsev MM The emperor's new wardrobe: rebalancing diversity of animal models in neuroscience research. Science 358, 466-469 (2017). [PubMed: 29074765]

228. Talakoub O, Gomez Palacio Schjetnan A, Valiante TA, Popovic MR \& Hoffman KL Closed-loop interruption of hippocampal ripples through fornix stimulation in the non-human primate. Brain Stimul. 9, 911-918 (2016). [PubMed: 27576185]

229. Palop JJ \& Mucke L Network abnormalities and interneuron dysfunction in Alzheimer disease. Nat. Rev. Neurosci 17, 777-792 (2016). [PubMed: 27829687]

230. Alvarado-Rojas C et al. Different mechanisms of ripple-like oscillations in the human epileptic subiculum. Ann. Neurol 77, 281-290 (2015). [PubMed: 25448920]

231. Bragin A, Mody I, Wilson CL \& Engel J Jr. Local generation of fast ripples in epileptic brain. J. Neurosci 22, 2012-2021 (2002). [PubMed: 11880532]

232. Gillespie AK et al. Apolipoprotein E4 causes age-dependent disruption of slow gamma oscillations during hippocampal sharp-wave ripples. Neuron 90, 740-751 (2016). [PubMed: 27161522]

233. Witton J et al. Disrupted hippocampal sharp-wave ripple-associated spike dynamics in a transgenic mouse model of dementia. J. Physiol 594, 4615-4630 (2014).

234. Altimus C, Harrold J, Jaaro-Peled H, Sawa A \& Foster DJ Disordered ripples are a common feature of genetically distinct mouse models relevant to schizophrenia. Mol. Neuropsychiatry 1 , 52-59(2015). [PubMed: 26417572]

235. Wiegand JP et al. Age is associated with reduced sharp-wave ripple frequency and altered patterns of neuronal variability. J. Neurosci 36, 5650-5660(2016). [PubMed: 27194342]

236. Gerrard JL, Burke SN, McNaughton BL \& Barnes CA Sequence reactivation in the hippocampus is impaired in aged rats. J. Neurosci 28, 7883-7890 (2008). [PubMed: 18667620]

237. Ul Haq R et al. Pretreatment with beta-adrenergic receptor agonists facilitates induction of LTP and sharp wave ripple complexes in rodent hippocampus. Hippocampus 26, 1486-1492 (2016). [PubMed: 27699900]

238. Ishikawa D, Matsumoto N, Sakaguchi T, Matsuki N\& Ikegaya, Y. Operant conditioning of synaptic and spiking activity patterns in single hippocampal neurons. J. Neurosci 34, 5044-5053 (2014). [PubMed: 24695722]

239. Nicole $\mathrm{O}$ et al. Soluble amyloid beta oligomers block the learning-induced increase in hippocampal sharp wave-ripple rate and impair spatial memory formation. Sci. Rep 6 , 22728(2016). [PubMed: 26947247]

240. Ciupek SM, Cheng J, Ali YO, Lu HC \& Ji D Progressive functional impairments of hippocampal neurons in a tauopathy mouse model. J. Neurosci 35, 8118-8131 (2015). [PubMed: 26019329]

241. Suh J, Foster DJ, Davoudi H, Wilson MA \& Tonegawa S Impaired hippocampal ripple-associated replay in a mouse model of schizophrenia. Neuron 80, 484-493 (2013). [PubMed: 24139046]

242. Phillips KG et al. Decoupling of sleep-dependent cortical and hippocampal interactions in a neurodevelopmental model of schizophrenia. Neuron 76, 526-533 (2012). [PubMed: 23141065] 
243. Carr MF, Karlsson MP \& Frank LM Transient slow gamma synchrony underlies hippocampal memory replay. Neuron 75, 700-713 (2012). [PubMed: 22920260]

244. Pfeiffer BE \& Foster DJ Autoassociative dynamics in the generation of sequences of hippocampal place cells. Science 349, 180-183 (2015). [PubMed: 26160946]

245. Iaccarino HF et al. Gamma frequency entrainment attenuates amyloid load and modifies microglia.Nature 540, 230-235 (2016). [PubMed: 27929004]

246. French RM Catastrophic forgetting in connectionist networks. Trends Cogn. Sci 3, 128-135 (1999). [PubMed: 10322466]

247. Hasselmo ME Avoiding catastrophic forgetting. Trends Cogn. Sci 21, 407-408 (2017). [PubMed: 28442279]

248. McCloskey M \& Cohen NJ in The Psychology of Learning and Motivation Vol. 24 (ed. Bower GH) 109-165 (Academic Press, 1989).

249. McClelland JL, McNaughton BL \& O'Reilly RCWhy there are complementary learning systems in the hippocampus and neocortex: insights from the successes and failures of connectionist models of learning and memory. Psychol. Rev 102, 419-457 (1995). [PubMed: 7624455]

250. Kumaran D, Hassabis D \& McClelland JL What learning systems do intelligent agents need? Complementary learning systems theory updated. Trends Cogn. Sci 20, 512-534 (2016). [PubMed: 27315762]

251. Hinton GE, Dayan P, Frey BJ \& Neal RM The "wake-sleep" algorithm for unsupervised neural networks. Science 268, 1158-1161 (1995). [PubMed: 7761831]

252. Mnih V et al. Human-level control through deep reinforcement learning. Nature 518, 529533(2015). [PubMed: 25719670]

253. Schaul T, Quan J, Antonoglou I \& Silver D Prioritized experience replay. Preprint at ArXiv http:// adsabs.harvard.edu/abs/2015arXiv151105952S (2015).

254. Pritzel A et al. Neural episodic control. Preprint at ArXiv http://adsabs.harvard.edu/abs/ 2017arXiv170301988P (2017).

255. Blundell C et al. Model-free episodic control. Preprint at ArXiv http://adsabs.harvard.edu/abs/ 2016arXiv160604460B (2016). 


\section{Retrograde amnesia}

An inability to access previously formed memories.

\section{Anterograde amnesia}

An inability to form new memories.

\section{Fear conditioning}

The process by which an animal learns to associate a cue (cued fear conditioning) or environment (contextual fear conditioning) with a negative outcome, such as a foot shock, and as a result expresses fear in response to the cue or environment alone.

\section{Recollection}

The conscious recall of a past experience.

\section{Stimulus-response association}

A conditioned relationship that supports an organism executing an action (the response) in reaction to a stimulus.

\section{Planning}

The process of setting future goals and determining the actions required to accomplish them, such as predetermining a route to a target location.

\section{Imagination}

The possibly subconscious mental act of considering possible future or alternative scenarios.

\section{Local field potential (LFP).}

The electrical potential measured by an extracellular electrode that results from the summed membrane currents of nearby neurons.

\section{Rapid eye movement (REM) sleep}

The 'paradoxical', wake-like phase of sleep that is marked by reduced synchrony in the LFP and Rem and that is associated in humans with dreaming.

\section{Slow-wave sleep}

The phase of sleep marked by low-frequency oscillations in the LFP that is strongly associated with memory consolidation.

\section{Trace eyeblink conditioning}

A hippocampus-dependent classical conditioning task in which a conditioned stimulus such as a tone or flash of light is followed, after a delay, by a blink-inducing unconditioned stimulus, such as a corneal air puff.

\section{Extinction}


A behaviourally defined loss of a previously learned association, typically thought to require new learning.

\section{Place fields}

A place field is the location in an environment where a given cell increases its rate of action potential firing when the animal is in that location.

\section{Place cells}

Pyramidal cells of the hippocampus that fire action potentials at a higher rate when the animal is in a particular location in an environment.

\section{NMDA receptor-mediated AMPA receptor trafficking}

The process by which glutamatergic NMDA receptor activation leads to preparation of glutamatergic AMPA receptors for insertion in the membrane to result in increased synaptic weight. 


\section{Box 1 |}

\section{Sharp wave-ripples across species}

The majority of sharp wave-ripple (SWR) and replay studies have been performed in mice or rats, but SWRs have also been described in vivo in cats ${ }^{212,213}$, bats $^{214}$, rabbits ${ }^{104,106}$, monkeys ${ }^{170,184,189,215,216}$ and humans ${ }^{150,217-219}$. SWR activity has also been described in the Australian bearded dragon (Pogona vitticeps), but in a region that is not considered to be a hippocampal analogue ${ }^{220}$, and whole zebrafish brains in vitro show SWR-like activity 221 . Although sequential replay has been observed only in rodents, the relationship described in rodents between SWRs and memory-dependent behaviour has also been reported in rabbits ${ }^{104,106}$, non-human primates ${ }^{184}$ and humans 217 .

Consistent with rodent findings ${ }^{8}$, human SWRs are most frequent during slow-wave sleep and immobility 222,223 and are correlated with widespread changes in activity throughout the brain. In macaque monkeys, a series of functional MRI studies identified activation of the neocortex and inhibition of subcortical structures at the time of SWRs ${ }^{170,224}$, as well as elevated activity following SWRs of the default-mode network ${ }^{225}$, which in humans is linked to memory processes, including imagination and prospection ${ }^{40,225}$. Differences between SWRs in rodents and in primates include a lower SWR rate in humans and monkeys ${ }^{215,217}$ (possibly owing to challenges inherent in primate SWR detection) and, in monkeys, the observation of SWRs during visual search, which is considered an analogue of active exploration ${ }^{184}$. This observation is at odds with thinking that, in rodents, exploration is associated with a theta rhythm and memory encoding ${ }^{7,226}$ more than with the SWR and its proposed memory functions.

A cross-species comparison of memory ability and features of the SWR, including state dependence and replay content, would potentially be informative for determining SWR function. Such a comparison will require further testing of the memory abilities of those species with SWRs ${ }^{227}$ and causal studies of the SWR in species other than rodents ${ }^{228}$. 


\section{Box 2 |}

\section{Sharp wave-ripples in disease and ageing}

An urgent goal of neuroscience is to understand diseases of the human brain, many of which share the symptom of debilitating memory loss. One explanation for this symptomatic overlap is that myriad cellular-level and molecular-level changes can cause dysfunction in the network-level activity patterns that support memory ${ }^{229}$. Identifying such emergent activity patterns presents the possibility of a therapeutic shortcut that is broadly effective: if activity patterns can be restored, even if the circuitry that naturally supports them cannot, memory could be restored.

The sharp wave-ripple (SWR) is a reasonable candidate for that approach. The first report of disrupted SWRs in disease was in human epilepsy ${ }^{8,219,230}$. Disrupted SWRs have since been reported in animal models of epilepsy ${ }^{69,231}$, Alzheimer disease ${ }^{232}$, dementia $^{233}$, schizophrenia ${ }^{234}$ and normal ageing 235,236 . Recent studies have demonstrated upregulation or downregulation of SWRs through neuromodulatory ${ }^{85,86,100,237}$ or other control ${ }^{238}$, suggesting possible therapeutic strategies.

However, given the diversity of findings in disease models for simple metrics such as the SWR rate $239-241$, success with this approach is likely to require identification of more specific patterns of disordered activity $69,233,235,241$. As an example, genetic and developmental mouse models of schizophrenia show disrupted sequential spiking activity during the SWR ${ }^{234,241}$ or decreased coordination of SWRs with cortical sleep spindles $^{242}$. In addition, a study of a knock-in mouse expressing the human APOE4 variant known to cause late-onset disease found learning and memory deficits that were associated with a deficiency in the normal slow gamma ${ }^{232}$ rhythm known to organize the activity of CA1 cells during the SWR ${ }^{243,244}$. A subsequent study found that rescuing the gamma deficit reduced the level of Alzheimer-disease-related amyloid- $\beta$ isoforms ${ }^{245}$, indicating that addressing network-level dysfunction could also resolve other disease symptoms. 


\section{Box 3 |}

\section{Repetition, sharp wave-ripple replay and machine learning}

Learning is supported by the repetition of experience, which has many names, including practice, study and training. Internally driven replay of neural activity representing an experience - a form of training without repetition of experience itself - can efficiently promote further learning because it enables easily adjusting the amount and the timing of training.

Such flexibility is an important point of similarity between artificial and biological learning systems; the brain's capacity for fast, flexible experience replay enables it to keep up with artificial systems and justifies the sharing of solutions between them. For instance, a foundational problem faced by any learning system, biological or artificial, is that of balancing stability and plasticity 246,247 . An early description of this problem was given in the context of connectionist systems, now known as neural networks, in which learned information is stored in the form of altered synaptic weights, as in the nervous system $^{248}$. In a highly stable system, a single instance of repetition will not drastically alter synaptic weights; here, new learning requires multiple exposures, and information cannot be acquired quickly. A more plastic system is the opposite and thus risks overweighting recent experience to result in 'catastrophic forgetting', the total erasure of previously stored information.

Presented as the brain's solution to this problem, the complementary learning systems model $^{249}$ described the updating of a stable neocortex by a plastic hippocampus through 'interleaved learning', wherein new information is incorporated gradually into existing knowledge through spaced repetition, now attributed mechanistically to hippocampal sharp wave-ripple replay ${ }^{250}$. Similar dual-network architectures were developed in artificial systems ${ }^{246}$. Hippocampal replay has since inspired other machine learning algorithms ${ }^{251}$, including the successful 'prioritized experience replay' used in training the Deep Q Network, in which rewarded events replay more often ${ }^{252,253}$.

In general, machine learning relies on repetition in the form of exposure to many events and, in some cases, multiple passes over the full training set, possibly with prioritization $^{254,255}$. These two forms of repetition are reminiscent of the brain's capacity to learn both from multiple examples of direct experience and from their replay, potentially complementary abilities that could provide insight into learning systems in general. 

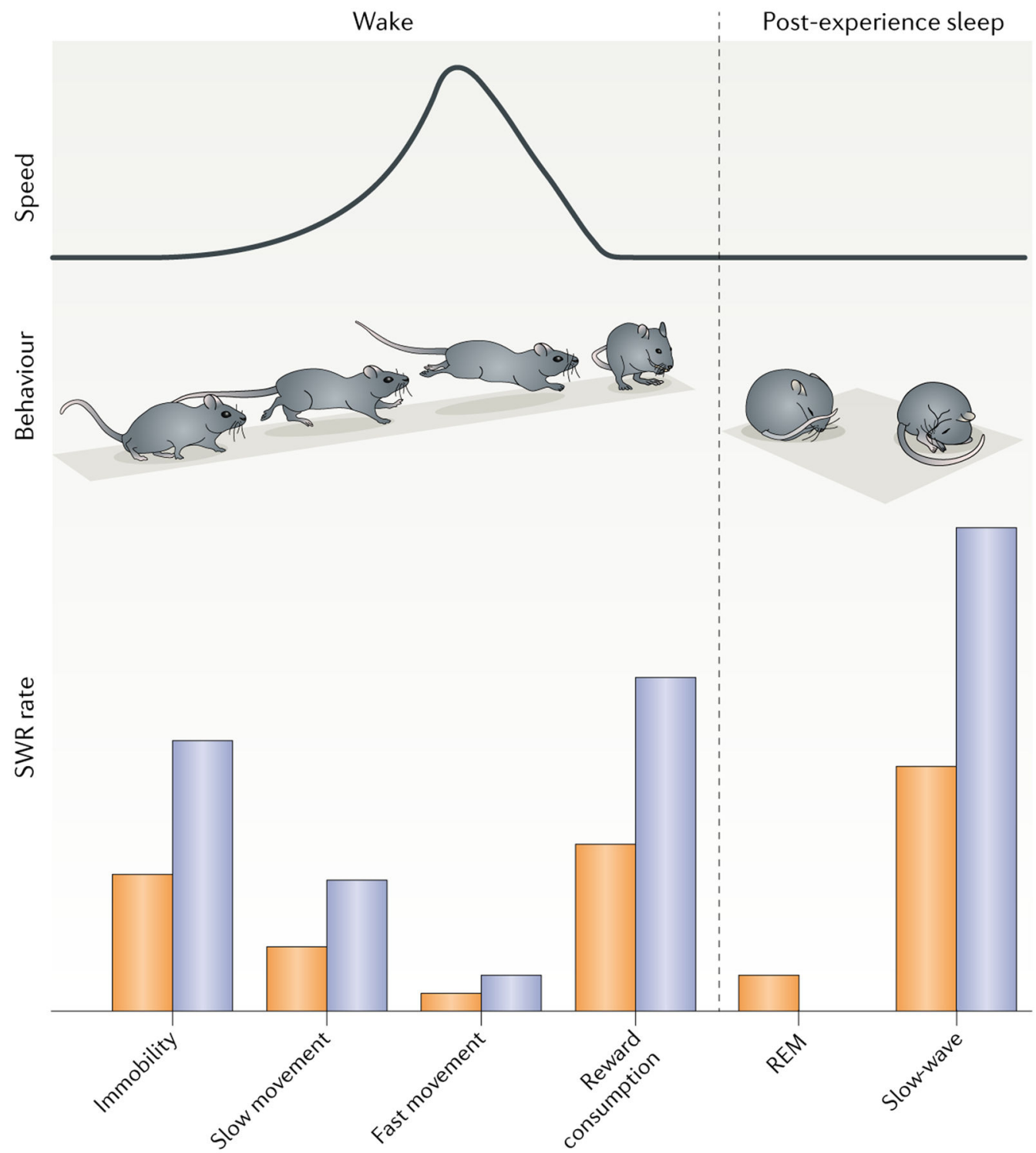

Novel environment

Familiar environment

Fig. 1 . Schematic of sharp wave-ripple rate across brain state and with movement speed. In the awake state, the sharp wave-ripple (SWR) rate varies as a function of movement speed, novelty and receipt of reward. SWRs are most common during periods of immobility and become increasingly rare at higher movement speeds. Their rate is higher across all speeds in novel versus familiar environments, and in both novel and familiar environments their rate is highest following receipt of reward. During sleep, SWRs occur only rarely during rapid eye movement (REM) sleep and occur most often during slow-wave sleep. The SWR rate during slow-wave sleep (in a familiar sleep box) following exploration of a novel environment is higher than it is following exploration of a familiar environment. The SWR rate in REM sleep has not been studied following experience in a novel environment, therefore it is omitted from the figure. These patterns of modulation are consistent with an 
increased SWR rate during and after learning and indicate that SWR-mediated retrieval is utilized primarily at lower speeds. 


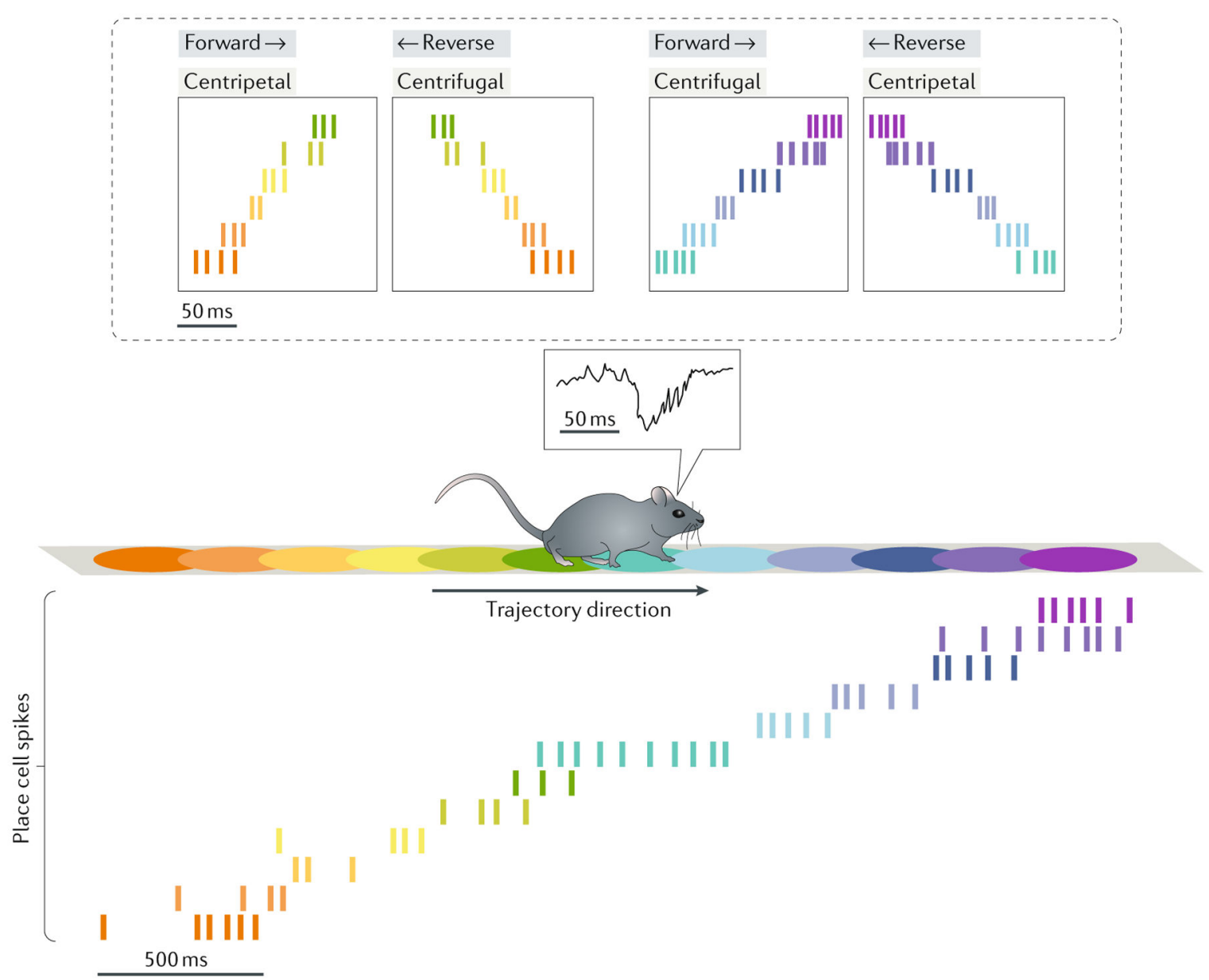

Fig. 2 |. Schematic of possible local replays: in the forward and reverse directions, centrifugally and centripetally.

Place cells increase their firing rates as a rat traverses the cells' respective place fields on a linear track from left to right (orange to purple). When the rat pauses, immobile, at the centre of the track, a sharp wave-ripple (SWR) occurs. Place cell activity during the SWR recapitulates recent experience, firing in the same order on a compressed timescale. Relative to the order of place cell firing during actual experience, these sequences can represent trajectories that are forward and centripetal (towards the rat); reverse and centrifugal (away from the rat); forward and centrifugal; or reverse and centripetal. Forward sequences are indicated by arrows beside the label 'forward' that are oriented in the same direction as the trajectory arrow (in this case rightward); reverse sequences, by contrast, are indicated by arrows in the direction opposite to the trajectory arrow. For centrifugal sequences, these arrows are oriented away from the rat; for centripetal sequences, the arrows are oriented towards the rat. If any of these sequences occurred before the rat actually traversed that track segment (as occurs more often in a less constrained environment with more path options), they would represent novel sequences. A second set of place cells with overlapping place fields, but that are preferentially active when the rat moves in the opposite direction (right to left), would participate in the same four replay types. If the rat ran on the track (middle 
panel), then the replays (top row) occurred when the rat was no longer on the track, and they would be classified as remote. 


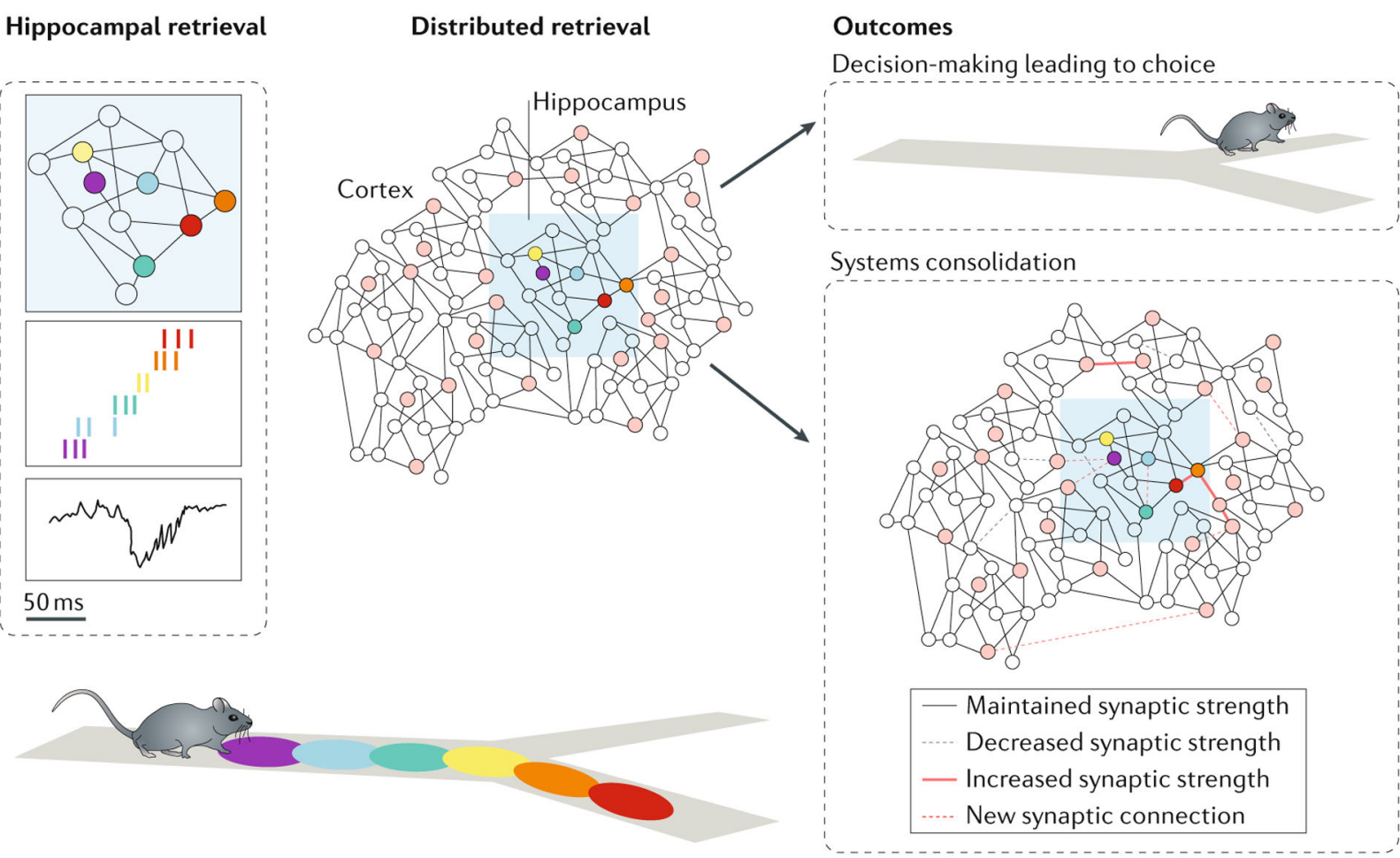

Fig. 3 |. Hypothesized function for sharp wave-ripples in retrieval of information from memory for immediate use and consolidation.

We hypothesize that retrieval, as it occurs here as the rat pauses on approach to a choice point, can be mediated by the sharp wave-ripple (SWR) (left panel, lower box), during which the ordered reactivation of place cells can represent trajectories previously experienced by the animal. Here, a centrifugal forward replay composed of activity from place cells with fields shown in purple to red is depicted (left panel, middle box). Nodes (left panel, top box) represent recorded hippocampal cells, and coloured nodes represent those place cells that spiked during the replay; they do not, as is true for many detected replay events, correspond to all the cells that likely participate in the replay event. The effect of replay activity in the hippocampus is the reactivation of activity in distributed networks outside the hippocampus (for example, the cortex; middle; red nodes indicate active neurons). The immediate effect of this on behaviour (top right) is to enable computations for decision-making leading to action; in this case, selection of the trajectory option that was not replayed. We propose that another long-term effect (bottom right) is the initiation of consolidation processes that can maintain (solid black lines), form (dashed red lines), strengthen (solid red lines) or renormalize (dashed black lines) synapses within the hippocampus, between the hippocampus and the cortex or within the cortex. Which of these effects will occur likely depends on neuromodulatory and other factors, subject to plasticity rules. We show here examples of possible changes: strengthened (solid red lines) or newly formed (dashed red lines) synaptic connections between pairs of active cells in the cortex (red nodes), between cells in the hippocampus (coloured nodes) or between cells in the hippocampus and cortex as well as weakened synaptic connections between cell pairs where one or both was inactive (white nodes). The maintenance of synaptic strength may also be 
supported by the SWR, potentially between any combination of active and inactive cells. The effect of these changes, which may contribute to systems consolidation, is to facilitate future retrieval events. It is possible that strengthened intracortical synapses could also eventually support memory retrieval independent of the hippocampus. 